\title{
PROCESOS DE ANULACIÓN DE MATRÍCULA Y DEVOLUCIÓN DE IMPORTES
}

\author{
Prof. Dra. Joana María Petrus Bey \\ Síndic de Greuges de la Universidad de las Islas Baleares \\ Prof. Dra. Elia Cambón Crespo \\ Defensora de la Universidad Europea de Madrid \\ Prof. Dra. Carmen Jiménez Salcedo \\ Defensora de la Universidad de Córdoba
}

\section{Introducción}

La cuestión de la anulación de matrícula no es un asunto menor en la normativa universitaria. Todas las universidades tienen regulado de una u otra manera el proceso de anulación de matrícula, y las normas que lo fijan afectan directamente a los estudiantes, principalmente, por influir en sus regímenes de permanencia, en el coste de sus futuras matrículas e incluso, en ocasiones, por afectar también el cálculo de la nota media de sus expedientes académicos.

El interés de tratar expresamente sobre los procesos de anulación de matrícula y la devolución de importes reside en el hecho de que en los últimos años las Defensorías Universitarias españolas hemos venido observando un aumento de casos de alumnos que por distintas razones no han podido hacer frente a alguno de los plazos de sus matrículas, o se han visto en la necesidad de solicitar la anulación de las mismas toda vez que no han obtenido beca, o bien han tenido que abandonar sus estudios por no poder hacer frente al encarecimiento experimentado por la subida de los precios públicos universitarios. Las situaciones que han enfrentado los alumnos en estas circunstancias han sido muy desiguales, pues las normativas universitarias que regulan las situaciones de impago y los procesos y efectos de la anulación de matrícula no son homogéneos. Analizar, pues, el espectro normativo en el que los Defensores hemos de resolver las quejas y consultas que se nos plantean en esta materia, nos permitirá reflexionar sobre las posibles mejoras que cada uno, viendo el conjunto, puede proponer en su propia universidad y, además, debatir colectivamente sobre cuáles son a nuestro juicios los principios elementales que deberían 
inspirar las normas reguladoras de los procedimientos de anulación de matrícula para que sus efectos académicos y económicos, sin perjudicar a la institución académica- no lesionen tampoco los derechos de los alumnos.

Es la pretensión de este texto, contribuir a dicho análisis y animar el debate para extraer de él conclusiones de interés común.

\section{El contexto actual en el que cabe enmarcar los procesos de anulación de matrícula}

El contexto de crisis económica que viene viviendo la sociedad española desde 2008, arroja unas cifras (vid. Gráfico 1) por todos conocidas que sitúan el paro, la disminución de ingresos per cápita, el número de familias sin recursos y los recortes en los servicios públicos básicos como sanidad y educación, entre las mayores preocupaciones de la clase media española ${ }^{1}$. El aumento de este tipo de quejas, e incluso de peticiones de amparo ante una administración universitaria no siempre suficientemente rápida en adaptar sus procedimientos y condiciones a las cambiantes situaciones socioeconómicas de su entorno, no puede sorprendernos.

La respuesta de las universidades españolas no ha contribuido a mejorar el panorama. Envuelto también el sistema universitario, especialmente sus universidades públicas, en un proceso de contención del gasto, reducción de la inversión en $\mathrm{I}+\mathrm{D}$, reducción de su financiación cuando no aumento del déficit, no parece haber estado en condiciones de responder a la crisis económica y a las altas tasas de paro -en especial juvenil- ofreciendo como cabría esperar una mejor formación y acceso a la enseñanza superior, pues la inversión en formación superior es, a juicio de los expertos, la vía más certera de salida a la crisis mundial (UNESCO, 2009) ${ }^{2}$.

El conjunto de universidades públicas se ha visto abocado a responder al contexto de crisis aplicando una subida de los precios públicos de sus servicios, (vid. Tabla 1) a la vez que ha extendido la política de numerus clausus a la práctica totalidad de sus titulaciones, lo que obviamente ha limitado el acceso a la educación superior, pues dichos incrementos no han ido acompañados del correspondiente aumento del número ni de la cuantía de las becas.

\footnotetext{
${ }^{1}$ Según Ramon Centeno (20-01-2014, Te interesa.es) "la clase media ha perdido un 30\% del valor de su patrimonio y un $10 \%$ de la renta en los último dos años". De acuerdo con el CIS, el paro y la corrupción son las dos principales preocupaciones de la población española. (http://www.cis.es/opencms/Archivos/Indicadores/ documentos_html/TresProblemas.html)

${ }^{2}$ En el caso de España, la OCDE (2012) constata que el grado de inserción laboral de los españoles es directamente proporcional al nivel de formación adquirido, de manera que el desempleo supera el 20\% entre la población que no finalizó la secundaria, frente a sólo el 10,4 entre los que finalizaron estudios universitarios.
} 


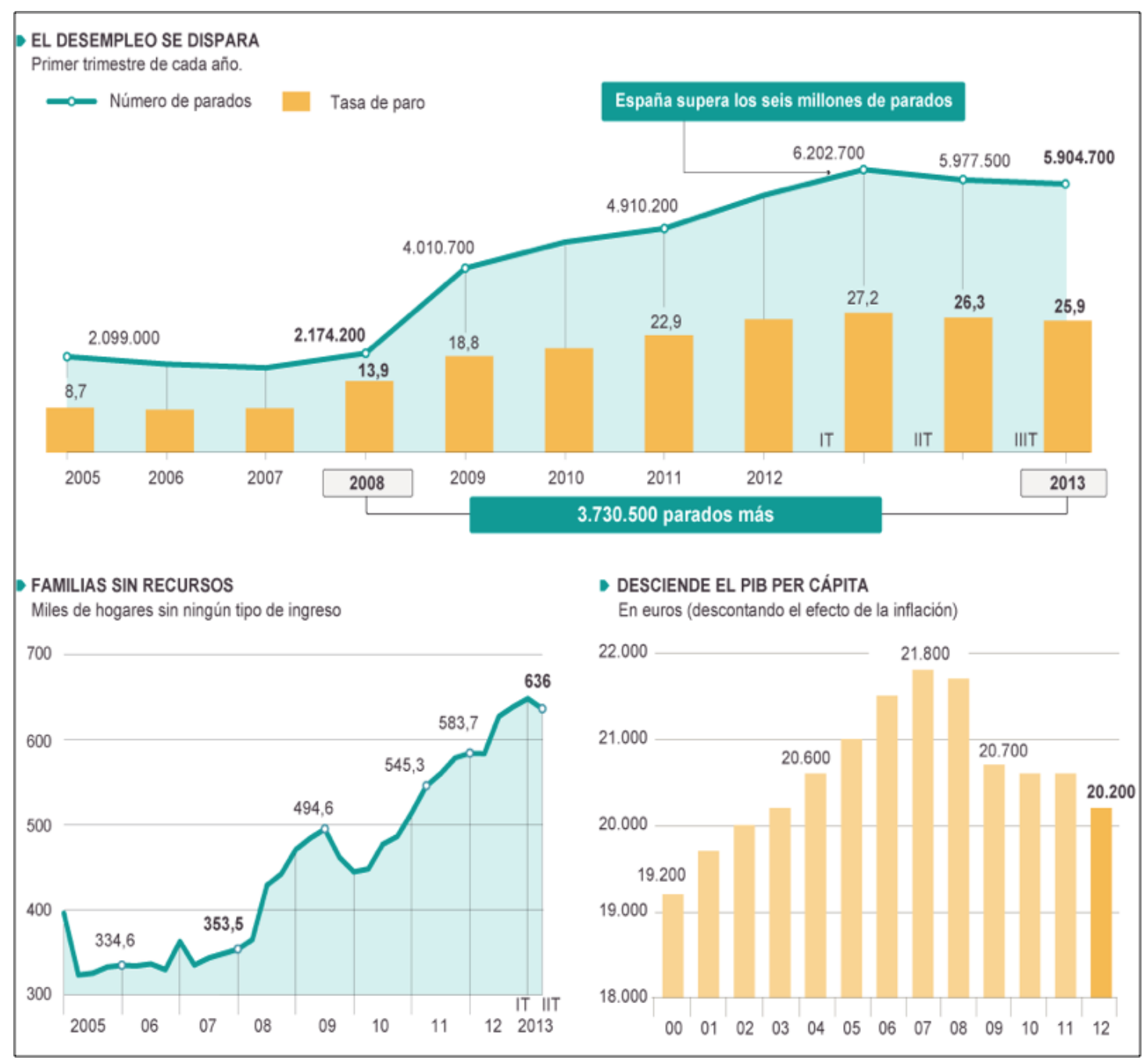

Gráfico 1. La crisis en cifras (2005-2013). Infografía: El País 24-02-2014

En este sentido, señalan J.F. Julià; J.A. Pérez y E. Melià (2014), citando a Hernández Armenteros y Pérez García (2012), en su artículo "El cambio necesario en la universidad española ante un nuevo escenario económico", que "para mantener la educación superior española dentro de criterios de equidad y de salvaguarda del principio de igualdad de oportunidades, es necesario que la reducción de la aportación de recursos públicos que puede permitir un incremento sostenido de los precios públicos, se combine con una aportación creciente para ampliar la política de becas (Hernández y Pérez, 2011)”.

El panorama de crisis ha afectado pues al conjunto de la economía española, pero en especial al Sector Público y es lógico por ello que en el contexto del sistema universitario español hayan sido las universidades públicas presenciales las que hayan sufrido mayores 
recortes y presenten mayores problemas de financiación, pues como señalan Hernández y Pérez (2011) "las universidades privadas se financian exclusivamente con los ingresos generados por la venta de sus servicios" ${ }^{\prime}$. En este contexto de crisis generalizada y de reducción en la financiación de los servicios públicos es lógico que los ingresos por matrícula adquieran una relevancia especial. Desde 1996, la financiación pública universitaria venía experimentado un crecimiento superior al registrado por el conjunto del PIB (HernándezPérez, 2011), por lo que en términos porcentuales, la aportación financiera directa de los usuarios de los servicios docentes se había ido reduciendo.

Así, la financiación vía transferencia corriente representaba en 2010 un 63,3\% del presupuesto, mientras que los ingresos por precios públicos suponían una media del 11,5\% ${ }^{4}$.

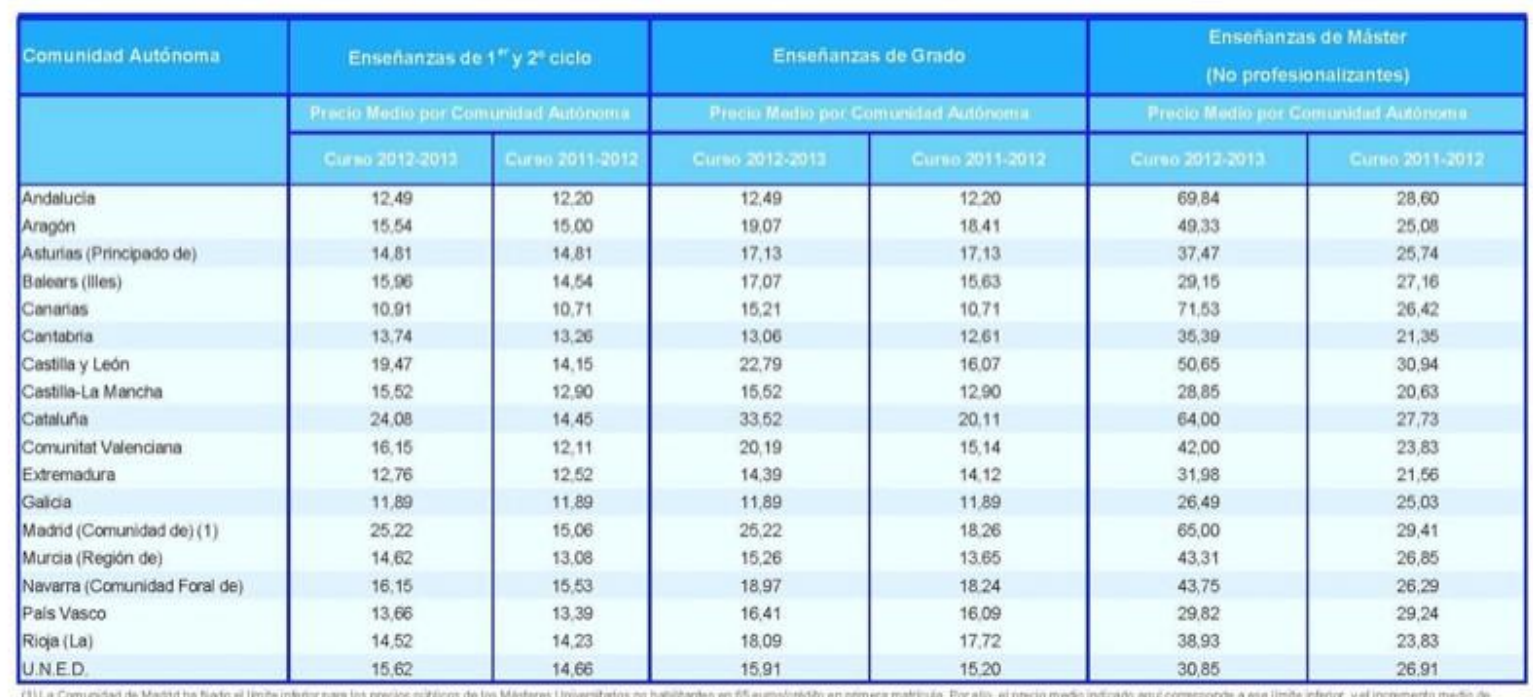

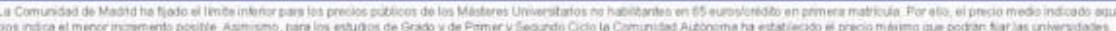

Tabla 1. Precios públicos medios del crédito matriculado por primera vez en titulaciones universitarias por Comunidad Autónoma (2011-12 y 2012-13)

Fuente: Ministerio de Educación. Estadística e informes universitarios

\footnotetext{
${ }^{3}$ Por su parte la UNED depende en exclusiva del Ministerio de Educación y por su singularidad no puede ser comparable con el resto de universidades públicas.

${ }^{4}$ En los datos que ofrece la CRUE, la media de ingresos correspondientes al capítulo 3 alcanza el 16,5\% pero se incluyen en él, además de los precios públicos, otros ingresos como los provenientes de los artículos 83 de LOMLOU y la venta de otros servicios. A este respecto, señalan Escardíbul y Oroval (2011) que para el conjunto de universidades públicas presenciales del estado los pagos realizados por los alumnos y sus familias representaban el curso 2008-09 el 16,3\% del total de ingresos de las universidades, aunque el porcentaje se reduce al 8,6\% si se consideran sólo los pagos por derechos de matrícula. Por su parte, si en lugar de considerar el total de ingresos, se tienen en cuenta exclusivamente los ingresos corrientes los porcentajes anteriores ascienden al $20,1 \%$ y $10,6 \%$ respectivamente.
} 
En la Tabla 2 puede verse qué representan los ingresos por matrícula dentro de ese capítulo 3 de ingresos corrientes de los presupuestos universitarios. Pese a la escasa relevancia cuantitativa que suponen los ingresos por matrícula en el conjunto del presupuesto de las universidades, máxime cuando sabemos que los servicios docentes son financiados en un $80 \%$ (de media) por el Sector Público (lo que reduce la aportación de los estudiantes a un 15-20\% del coste real de sus estudios), la Administración Pública universitaria ha sido siempre especialmente reacia a practicar una política flexible en cuanto a medios de cobro y pago de los precios públicos y a la anulación de matrícula.

\begin{tabular}{|lrrr}
\hline Comunidad autónoma & $\begin{array}{r}\text { Precios públicos } \\
\text { + tasas/ ingresos corrientes }\end{array}$ & $\begin{array}{r}\text { Prestación de servicio } \\
\text { / ingresos corrientes }\end{array}$ & $\begin{array}{r}\text { Transferencias corrientes de } \\
\text { CC.AA. / ingresos corrientes }\end{array}$ \\
\hline Andalucia & $12,7 \%$ & $4,3 \%$ & $74,8 \%$ \\
\hline Aragón & $17,4 \%$ & $3,5 \%$ & $70,1 \%$ \\
\hline Asturias & $17,1 \%$ & $0,4 \%$ & $77,7 \%$ \\
\hline Islas Baleares & $15,1 \%$ & $2,4 \%$ & $75,7 \%$ \\
\hline Canarias & $11,3 \%$ & $0,9 \%$ & $82,6 \%$ \\
\hline Cantabria & $10,9 \%$ & $12,0 \%$ & $69,7 \%$ \\
\hline Castilla - La Mancha & $10,6 \%$ & $2,9 \%$ & $78,2 \%$ \\
\hline Castilla y Lé́n & $14,3 \%$ & $4,1 \%$ & $75,3 \%$ \\
\hline Cataluna & $15,4 \%$ & $6,6 \%$ & $67,9 \%$ \\
\hline Comunidad Valenciana & $11,2 \%$ & $5,3 \%$ & $78,9 \%$ \\
\hline Extremadura & $16,2 \%$ & $4,5 \%$ & $76,6 \%$ \\
\hline Galicia & $12,6 \%$ & $6,5 \%$ & $73,8 \%$ \\
\hline Madrid & $17,2 \%$ & $4,2 \%$ & $72,8 \%$ \\
\hline Murcia & $14,6 \%$ & $5,0 \%$ & $75,6 \%$ \\
\hline Navarra & $13,2 \%$ & n.d. & $82,8 \%$ \\
\hline Paí Vasco & $9,4 \%$ & $3,4 \%$ & $72,6 \%$ \\
\hline La Rioja & $11,6 \%$ & $0,9 \%$ & $82,6 \%$ \\
\hline Uned & $48,5 \%$ & $0,3 \%$ & \\
\hline n.d: No disponble. & & & \\
\hline
\end{tabular}

Tabla 2. Detalle de los ingresos de los presupuestos liquidados de las universidades públicas españolas (2010, en euros). Fuente: Michavila, F. (2012): La Universidad Española en cifras”. CRUE

3. Naturaleza de la anulación de matrícula y de la devolución de los precios públicos.

La necesidad de regular los procesos de anulación de matrícula nace indudablemente del interés de la institución universitaria por establecer en qué condiciones, bajo qué supuestos y con qué efectos podrá disolverse el acto previo de "matriculación", que debe tenerse por establecido al hablar de la posibilidad de anularlo.

Las Universidades, bien a través de su propia normativa, bien en cumplimiento de la normativa estatal o autonómica, tienen claramente establecido el proceso de "matrícula", 
pues dicho procedimiento permite formalizar la relación entre unos potenciales estudiantes y la institución misma para que esta última pueda prestar los servicios de educación superior y los primeros recibirlos. El acto de matriculación puede considerarse a efectos prácticos un "contrato", que se celebra de forma voluntaria entre las partes, aunque sin que exista entre ellas un plano de igualdad como sucedería de producirse el acuerdo en el marco de una relación civil o mercantil. La Universidad conserva en este caso la prerrogativa de las administraciones públicas de establecer de forma unilateral las condiciones en que va a permitir la contratación de sus servicios, aunque el acto en sí de matricularse haya de contar necesariamente con la voluntad de quien desea convertirse en estudiante, por lo que la matriculación, confiere al acto de matricularse una naturaleza bilateral.

Por el contrario, el acto de "anulación" de matrícula reviste una complejidad mayor, pues puede producirse de forma unilateral por parte de la universidad (en determinados supuestos tasados), sin que al estudiante le quepa más que la vía de la interposición de recursos administrativos o contenciosos en caso de no estar conforme con la anulación, o puede producirse a instancia del propio estudiante, en cuyo caso no bastará su mera voluntad para lograr la anulación, sino que necesariamente deberá contar con el ejercicio potestativo de la administración universitaria para que su petición de anulación resulte efectiva.

Es habitual, por lo anteriormente expuesto, que en la normativa sobre anulación de matrícula se distinga entre los "efectos académicos" y los "efectos económicos" de esta anulación, pues de un lado la anulación comporta efectos sobre la trayectoria académica (permanencia, convocatorias, etc.) y de otro comporta efectos económicos (pago de segundas matrículas, devolución de importes, etc.). Analizaremos más adelante con más detalle la tipificación que hacen las universidades de los supuestos en que considerarán procedente la anulación de los efectos académicos de la anulación total/parcial de la matrícula así como de los efectos económicos. No obstante, cabe señalar aquí como recordatorio del marco jurídico en el que las universidades públicas pueden proceder a la devolución de precios públicos, una aclaración que consideramos básica en torno a las posibilidades jurídicas de la devolución de importes.

3.1. Marco normativo. Momento y circunstancias en que puede estimarse la devolución de matrícula.

Dentro del sistema público, las universidades no pueden fijar libremente el momento ni las circunstancias en que estimarán procedente devolver el importe íntegro de la matrícula 
abonada por los estudiantes. La estimación de la devolución total o parcial del importe abonado en concepto de matrícula lógicamente sólo podrá realizarse si previamente ha existido y se ha estimado una petición de anulación de matrícula con efectos académicos, ya que no puede suceder que se estime la devolución del importe de una matrícula que no haya sido anulada académicamente. La única excepción a esta situación es que la matrícula se haya cobrado por parte de la Universidad de forma indebida (a un estudiante que disfruta de una beca, a un estudiante con derecho a exención de matrícula, etc.), en cuyo caso sí sería procedente estimar la devolución del importe de la matrícula sin que existiera anulación académica.

Teniendo pues por supuesto el caso de un estudiante que tras haber solicitado y conseguido la anulación académica de su matrícula solicite además la devolución de los precios públicos satisfechos, cabe decir que en el sector público, y en materia económica, las universidades deben atenerse a lo dispuesto en un marco normativo amplio en el que, sin ánimo de exhaustividad, cabe destacar:

- Ley 8/1989, de 13 de abril, de tasas y precios públicos (BOE del 15 de abril de 1989), modificada por la Ley 25/1998, de 13 de julio, de modificación del régimen legal de las tasas estatales y locales y de reordenación de las prestaciones patrimoniales de carácter público (BOE de 14 de julio).

- Ley 13/1982 de 7 de abril, de integración social de los minusválidos.

- Ley 32/1999, de 8 de octubre (BOE del 9 de octubre), de solidaridad con las víctimas del terrorismo.

- Ley 40/2003, de 18 de noviembre (BOE del 19), de Protección a las Familias Numerosas.

- Real Decreto 288/2003, de 7 de marzo, por el que se aprueba el Reglamento de ayudas y resarcimientos a las víctimas de delitos de terrorismo.

- Ley Orgánica 1/2004, de 28 de diciembre, de Medidas de Protección Integral contra la Violencia de Género, BOE del 29-12-2004.

- Ley Orgánica 5/2001, de 21 de diciembre de Universidades modificada por la Ley Orgánica 4/2007, de 12 de abril (artículo 45).

A esta normativa estatal, deberá añadirse la legislación que en su caso corresponda a cada comunidad autónoma, en la que se incluye por supuesto lo que disponga anualmente en 
cada comunidad el Decreto de Precios Públicos para los servicios universitarios de las universidades bajo su jurisdicción.

De la normativa estatal, cabe señalar que la Ley 8/1989, de 13 de abril, de tasas y precios públicos entró en vigor cuando las universidades estaban regidas por la Ley Orgánica 11/1983, de 25 de agosto, de reforma universitaria (LRU), de modo que la propia Ley 8/1989 estableció en la disposición adicional quinta la adaptación a la LRU, señalando que las tasas académicas y demás derechos a que se refiere la letra b) del apartado 3 del artículo 54 de la Ley Orgánica 11/1983, de 25 de agosto, de Reforma Universitaria, tendrían la consideración de precios públicos y se fijarían y regularían de acuerdo con lo establecido en el citado artículo. La Ley 8/1989 abrió pues ya la puerta a que las denominadas en la propia Ley Orgánica de Universidades "tasas universitarias" fueran consideradas "precios públicos" y, por tanto, a que las "tasas universitarias" no pudieran ser consideradas "tributos", ni los ingresos generados por ellas "ingresos tributarios".

A raíz de una sentencia del Tribunal Constitucional (STC 185/1995), bien conocida entre los especialistas en materia fiscal, la Ley 8/1989 tuvo que ser modificada (en concreto los artículos 6, 10, 15, 16, 19, 20 , 24, 25, 26 y 27) mediante la Ley 25/1998, de 13 de julio, de modificación del régimen legal de las tasas estatales y locales y de reordenación de las prestaciones patrimoniales de carácter público (BOE de 14 de julio). En esencia, la nueva ley estableció que los precios públicos deben cumplir simultáneamente dos requisitos: que el servicio o la actividad administrativa que se solicite sea producto de una voluntad real, libre y espontánea del interesado y que este servicio o actividad no se preste por los entes de Derecho público en situación de monopolio de hecho o de derecho. Si no concurren ambas circunstancias estos precios públicos, en tanto que son de hecho o de derecho-coactivos y obligados para los interesados, adquieren carácter de tributo (tasa) de modo que para que sea legal su imposición esta debe regularse por ley, mientras que los precios públicos, en tanto que regulan servicios o actividades voluntarias y no monopolísticas prestadas por los entes públicos, se pueden aprobar con normativas de rango inferior.

Por otra parte, el artículo 81 de la Ley Orgánica 6/2001, de 21 de diciembre, de universidades, considerando la modificación introducida por la disposición adicional quinta de la Ley Orgánica 4/2007, de 12 de abril, establece que los precios públicos para los estudios que conducen a la obtención de un título universitario los fija la Comunidad Autónoma dentro de los límites que establezca la Conferencia General de Política Universitaria que estarán relacionados con los costes de prestación del servicio. 
Estos párrafos aclaratorios son necesarios para entender que el importe de la matrícula que paga un alumno para obtener la prestación de los servicios universitarios resulta del

La Ley Orgánica 8/1989 de Universidades abrió la puerta a que las denominadas "tasas universitarias" fueran considerados "precios públicos" y que por ellos los importes pagados por los estudiantes en sus matrículas no pudieran ser considerados "tributos" ni los ingresos generados por éstas "ingresos tributarios". Esta distinción es fundamental para entender el carácter contractual y voluntario del proceso de matrícula y de su anulación. establecimiento de un precio público que es legalmente fijado por un decreto que aprueba anualmente la Comunidad Autónoma de la que depende el ente universitario. El hecho de que impropiamente se hable aún de "tasas" universitarias, no nos puede hacer desconocer que legalmente, como hemos visto, los servicios universitarios están sujetos

al pago de "precios públicos". Esta distinción es esencial en la medida en que está revelando que la naturaleza del servicio por el que se abona la matrícula tiene un carácter contractual y voluntario para quien lo paga (el alumno) y también que este servicio no es prestado de forma exclusiva por el sector público. En efecto, como bien sabemos, los servicios académicos universitarios no son de imposible prestación por el sector privado ni se encuentran reservados en exclusiva al sector público, de la misma forma su pago, fruto de la contratación, es voluntario y el servicio que se obtiene expresa la libre voluntad del alumno de contraer la obligación de pagar por él. La sentencia del Tribunal Constitucional fue muy clara al respecto: "los servicios académicos no pueden dar lugar a la exigencia de tasas, ya que los únicos niveles en que su recepción resulta obligatoria son los protegidos por la gratuidad de la enseñanza, impidiéndose la exigencia de tasas por razón de los mismos”.

Aclarado este aspecto clave, es lógico retomar el asunto inicial de en qué momento y bajo qué supuestos resultará procedente la devolución del importe pagado en concepto de matrícula. Toda vez que se ha establecido que la devolución del importe de la matrícula (de una o más asignaturas) equivale a la devolución de un "precio público" será suficiente con remitirse a la Ley 8/1989, de 13 de abril, de tasas y precios públicos en su texto ya modificado por la Ley 25/1998 de 13 de julio y leer el artículo 27 (Administración y cobro de los precios públicos). El artículo 27 de la Ley dispone que los precios públicos podrán exigirse desde que se inicia la prestación de servicios que justifica su exigencia" (27.2) y que "cuando por causas no imputables al obligado al pago del precio público no se preste el servicio o no se realice la actividad, procederá la devolución del importe que corresponda o, tratándose de espectáculos, el canje de las entradas cuando ello sea posible" (artículo 27.5). 
De este artículo se deduce que basta con que se produzca el inicio de la actividad para que nazca el deber de pagar el precio del servicio que ha contratado. Sensu contrario, no se puede exigir el pago del precio del servicio hasta que no se inicie la prestación de servicios (lo que no debe interpretarse como imposibilidad de que la universidad cobre la matrícula "por adelantado", antes de iniciar la prestación del servicio, sino como imposibilidad de que lo exija; así, con anterioridad al inicio del servicio puede establecer las condiciones de pago "previo" que estime oportunas ya que si son aceptadas por quien contrata libremente el

De acuerdo con la Ley 8/1989, de 13 de abril, de tasas y precios públicos, “los precios públicos podrán exigirse desde que se inicia la prestación de servicios que justifica su exigencia”, de manera que el pago anticipado de la matrícula es una condición contractual libremente aceptada, por lo que si la anulación de matrícula se produce antes de iniciarse la prestación de servicios, queda plenamente justificada la devolución de la totalidad del importe satisfecho.

\begin{abstract}
servicio el pago anticipado no supone ninguna ilegalidad 5 .

Surge entonces la cuestión de cuál es el momento real en que se inicia el servicio académico universitario que el alumno ha contratado cuando se ha matriculado; se podría argumentar que los primeros trámites en los servicios administrativos ya suponen el inicio del servicio pero no hay duda de que la
\end{abstract}

fecha de inicio de las clases y el quehacer docente de las primeras semanas deben considerarse en sentido amplio el comienzo "real" de la prestación del servicio académico que es la educación superior. Este periodo, como veremos, vendrá pues a coincidir con lo que la mayoría de universidades tienen fijado para solicitar la anulación parcial o total de matrícula sin necesidad de justificación y con derecho a devolución de los importes satisfechos, por lo que dentro de este periodo resultaría a nuestro juicio totalmente procedente devolver el importe pagado.

Una vez iniciada la actividad o la prestación del servicio sólo procederá devolución del importe si el servicio no se presta o la actividad no se realiza "por causa no imputable al obligado al pago del precio público". La interpretación de esta frase es clave para dilucidar si el obligado al pago, en nuestro caso el alumno, tiene derecho o no a la devolución del importe de la matrícula una vez que se ha iniciado el curso, ya que con anterioridad al inicio ya hemos visto que sí. Aceptando una interpretación muy restrictiva y literal del redactado, debería decirse que no procede devolver el importe si el servicio se ha prestado o la actividad se ha realizado, ya que el simple abandono voluntario de la actividad (asistencia a clase cabe entender) para

\footnotetext{
5 Ello daría pie a discutir si un posible contratante del Servicio pudiera solicitar no hacer efectivo el pago hasta el momento de iniciar la prestación del Servicio.
} 
parte del alumno no significa que la administración universitaria haya dejado de realizar la actividad. Sin embargo, que la devolución sea procedente cuando el servicio no se preste por causa no imputable al obligado al pago no significa, "sensu contrario", que no proceda en ninguna circunstancia devolver el importe cuando el servicio no se preste o la actividad no se realice por causa no imputable al ente público, en este caso, la universidad.

Resulta razonable pensar que si la ley hubiera querido decir que "sólo procederá la devolución del importe que corresponda cuando no se preste el servicio o no se realice la actividad por causa imputable al ente de derecho público que deba realizarlo ", simplemente, lo hubiera redactado así. Debemos pensar entonces que cuando la ley establece que procederá la devolución cuando no se realice la actividad y no se preste el servicio "por causa no imputable al obligado al pago" entiende que entre estas causas se incluyen aquellas en las que el obligado al pago se ve privado de la prestación del servicio que ha pagado por hechos que sin ser atribuibles a quien debió prestar el servicio tampoco lo son a su voluntad.

En efecto, el artículo 27 de la Ley 8/1989 (en su redacción modificada según lo dispuesto en la Ley 28/1995) distingue entre el supuesto de que no se realice la actividad y que no se preste el servicio, lo que permite considerar que, aunque la actividad se produzca, si el servicio no puede ser recibido por el obligado al pago y por causas no imputables a él, entonces sí procede la devolución del precio público, porque no habrá sido posible prestarle el servicio por el que pagó por causas, por así decirlo, ajenas a su voluntad (aunque estas causas no sean imputables tampoco a la universidad).

Esta es necesariamente la interpretación subyacente que encontramos en los supuestos que la mayoría de universidades tienen tipificados -como veremos- como procedentes para devolución del importe de la matrícula: obtención de plaza en otra universidad enfermedad grave, o accidente, situaciones laborales o familiares sobrevenidas, denegación del visado, etc. Como vemos, con la excepción de la obtención de plaza en otra universidad, para lo que obviamente es necesaria la voluntad expresa del sujeto que la solicite, el resto de causas son todas ellas involuntarias o ajenas a la voluntad del obligado al pago (el alumno), aunque tampoco sean imputables a la universidad.

\section{Resultados de la Encuesta realizada entre las Universidades}

Con la intención de conocer con más detalle cómo tienen establecidas las universidades las formas de matrícula, de anulación de matrícula y las devoluciones de precios públicos se 
solicitó la colaboración de los defensores universitarios en la realización de una encuesta cuyos principales resultados se ofrecen en este $\operatorname{apartado}^{6}$.

\begin{tabular}{|c|c|}
\hline \multicolumn{2}{|l|}{ Mie mbros CEDU } \\
\hline \multicolumn{2}{|l|}{ Total universidades } \\
\hline Encuestas contestadas & 37 \\
\hline$\%$ participación & $60 \%$ \\
\hline Total Universidades públicas & 47 \\
\hline Encuestas contestadas por U. Públicas & 29 \\
\hline$\%$ participantes & $62 \%$ \\
\hline Total Universidades privadas & 15 \\
\hline Encuestas contestadas por U. Privadas & \\
\hline$\%$ participantes & $53 \%$ \\
\hline
\end{tabular}

Tabla 3. Universo de la encuesta. Datos básicos

La encuesta ha contado con un total de 32 preguntas divididas en cinco secciones:

I. Datos identificativos de la Universidad (nombre y tipo de financiación públicaprivada. Preguntas 1-2).

II. Formas de pago de la matrícula: fraccionamiento, modalidades, bonificaciones, pago a la carta, etc. distinguiendo el caso de los alumnos a los que se les ha denegado la beca (preguntas 3-9).

III. Reducción y devolución de los precios de matrícula (preguntas 10-11).

IV. Anulación de matrícula: situaciones que dan lugar a la anulación a instancia de la universidad o del estudiante, efectos del impago, consecuencias académicas y económicas de la anulación (preguntas 12-24).

V. Procedimiento de notificación: vía, consentimiento, contenido de la notificación, recursos (pregunta 25-32).

La encuesta ha sido respondida por 29 universidades públicas de un total de 47 (62\%) y por 8 universidades privadas de un total de 15 (53\%).

Cabe decir que las encuestas recibidas han sido depuradas eliminando las incompletas y duplicadas, lo que arroja un total de 37 encuestas válidas (vid. Tabla 3), es decir, una

\footnotetext{
6 Debe señalarse que la encuesta se cerró en el mes de octubre de 2014, por lo que desde entonces la situación puede haber cambiado en algunas universidades al haberse regulado algunos aspectos de los aquí analizado de forma distinta desde entonces, bien en los Decretos de Precios públicos aprobados por las respectivas comunidades autónomas, bien por la entrada en vigor de normativa interna de las universidades en aquellos aspectos no regulados por normativa de la comunidad.
} 
participación del $60 \%$. El hecho de que no todas las preguntas hayan sido contestadas por todos los encuestados (por desconocer el dato, o por no proceder) explica que en algunas preguntas el número de respuestas sea inferior al del universo encuestado, por lo que al estar trabajando con un universo de referencia en ocasiones muy pequeño, hay que tomar con prudencia los datos relativos, ya que en estos casos, una pequeña variación en los valores absolutos produce un brusco cambio en el valor relativo. El anexo del final del documento incluye las respuestas a las preguntas abiertas que se formularon en la encuesta.

\subsection{Formas de pago}

El primer conjunto de preguntas, agrupadas bajo el epígrafe "Formas de pago", pretende conocer las facilidades que dan las universidades a los estudiantes para hacer frente al pago de su matrícula. La primera de las facilidades consideradas es la de permitir fraccionar el pago, considerado las condiciones más ventajosas cuanto mayor sea el número de plazos permitido.

\begin{tabular}{|c|c|c|}
\hline \multicolumn{3}{|c|}{ ¿Es posible el pago fraccionado? } \\
\cline { 2 - 3 } Sí & 36 & $97 \%$ \\
\cline { 2 - 3 } No & 1 & $3 \%$ \\
\hline Públicas & \multicolumn{3}{|}{} \\
\cline { 2 - 3 } Sí & 29 & $100 \%$ \\
\cline { 2 - 3 } No & 0 & \\
\cline { 2 - 3 } Privadas & \multicolumn{3}{|}{} \\
\cline { 2 - 3 } Sí & 7 & $47 \%$ \\
\cline { 2 - 3 } No & 1 & $7 \%$ \\
\hline
\end{tabular}

Tabla 4. Existencia o no de pago fraccionado

De las universidades participantes en la encuesta, sólo una no permite el pago fraccionado, de manera que puede entenderse universal la posibilidad de fraccionar el pago. Ahora bien, cuando se pregunta en cuántos plazos es posible fraccionar el pago, el panorama empieza a presentar matices.

En términos relativos, podemos afirmar que un $61 \%$ de las universidades ofrecen la posibilidad de fraccionar en 5 plazos o más los importes de matrícula, lo que debe valorarse muy positivamente (vid. Gráfico 2). Pese a ello, persisten un grupo de universidades, todas ellas públicas, que no han adaptado todavía sus formas de pago tradicionales al contexto actual, por lo que no permiten más de dos o a lo sumo tres plazos. 


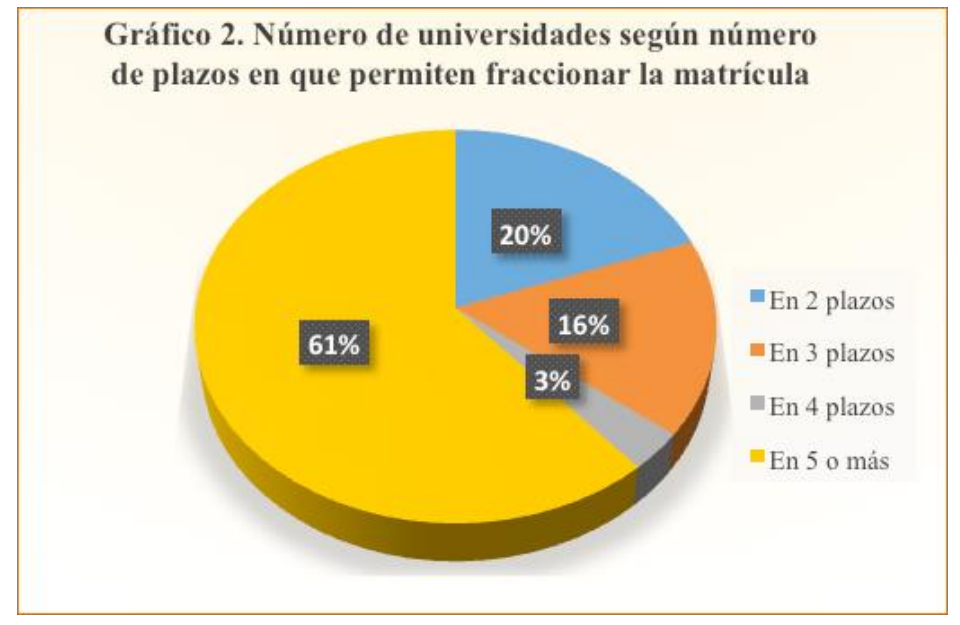

Se observa en general que las universidades privadas y las públicas localizadas en las CCAA de Andalucía, Madrid, Barcelona, Murcia y Extremadura, las que ofrecen 5 plazos o más a los estudiantes para pagar sus matrículas ${ }^{7}$, sin que ello comporte un sobrecoste.

Algunas universidades ofrecen además la posibilidad de aumentar el número de plazos (entre 7 y 10) acogiéndose a la fórmula de solicitar un préstamo a bajo interés a una entidad financiera facilitada por la propia universidad. Es el caso de la Universidad Politécnica de Cataluña.

Todas las universidades ofrecen la posibilidad de pagar de una sola vez sin que dicho pago comporte bonificación alguna en un 91\% de las universidades. Sólo en 3 universidades, todas ellas privadas, se ofrecen descuentos del $2 \%$, $3 \%$ y $4 \%$ sobre el precio total de matrícula por pago único.

Las condiciones para poder acogerse al pago fraccionado no son homogéneas ${ }^{8}$. El 71\% establece como condición que sólo puede fraccionarse domiciliando los recibos en una entidad bancaria y siempre que la cantidad aplazada supere un cierto importe. Las condiciones son generales para todos los estudiantes, con independencia de su nacionalidad o residencia.

\footnotetext{
${ }^{7}$ UPV, UJI, UJA, UCM, UdG, UOC, UB, UB, UPM, URJC, UEM, UM, UUPF, UAL, UIC, UPO, UPC, IE Universidad, UDeusto, UAH, USJorge, UEx.

${ }^{8}$ Con respecto al pago aplazado, el $14 \%$ de las universidades (es decir, 5) contestaron que sí; en el resto -31 universidades- no se considera. En la UM existe un recargo de $7 €$ si se opta por 7 plazos (aunque sin recargo si
} 
se opta por 3 plazos); en la UPC, existe el pago fraccionado como en el resto de universidad, o se considera la opción de un préstamo de matrícula al 4,99\% de interés mensual.

\begin{tabular}{|c|c|c|c|}
\hline Condiciones más habituales para permitir el pago aplazado & & Sí & No \\
\hline Restringido a la ampliación de matrícula & 23 no & & $64 \%$ \\
\hline Cuando el importe de la liquidación supere un cierto importe & $11 \mathrm{si} 26 \mathrm{no}$ & $30 \%$ & $70 \%$ \\
\hline Solo mediante domiciliación bancaria & 22 si 9 no & $71 \%$ & $29 \%$ \\
\hline Sólo pago directo en entidad financiera & 3 sí 21 no & $13 \%$ & $88 \%$ \\
\hline Sólo para estudiantes residentes en España & 1 sí22 no & $4 \%$ & $96 \%$ \\
\hline
\end{tabular}

Tabla 5. Condiciones en el pago aplazado

\subsubsection{Solicitantes de beca y modalidades de pago}

Hemos querido conocer también en qué medida haber solicitado una beca y no haber obtenido su concesión afecta al pago de la matrícula. Es bien conocido que los estudiantes que solicitan beca formalizan la matrícula como solicitantes de beca, lo que por lo general significa que no tienen que hacer frente al pago de la matrícula hasta no conocer la resolución definitiva de la convocatoria de becas.

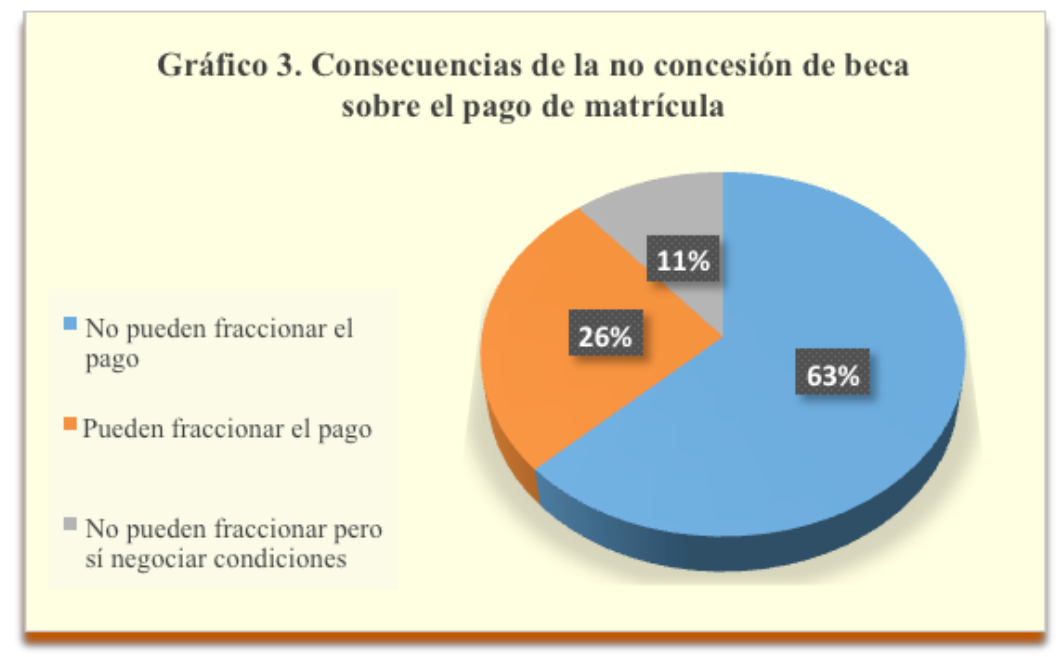

Una vez publicada la resolución de las becas, aquellos alumnos que no hayan resultado beneficiarios deberán hacer frente al pago de su matrícula, pero ¿en qué condiciones? Como puede observarse en el Gráfico 3, sólo un 26\% de las universidades permiten a estos alumnos fraccionar el pago de su matrícula, mientras que un $74 \%$ no lo permite, aunque algunas universidades (11\%) contemplan la posibilidad de "negociar" de forma particular las condiciones de pago. 
Muy oportunamente, algunas universidades ofrecen una explicación de por qué se deniega a los solicitantes de beca fraccionar el pago de su matrícula en el caso de que la beca no les sea concedida o bien les sea revocada. En efecto, todas ellas coinciden en señalar que 1 resolución tardía de las becas hace inviable optar al pago fraccionado, pues para cuando los alumnos conocen la resolución definitiva ya ha transcurrido buena parte del curso y han vencido o la totalidad de los plazos o la mayoría de ellos, por lo que los solicitantes de beca que no la consiguen, tienen unas condiciones de pago distintas y menos favorables que aquéllos estudiantes que no la solicitaron.

Una resolución más temprana de la convocatoria de las Becas generales al estudio permitiría, de un lado, incorporar más prontamente a las universidades los ingresos correspondientes a los estudiantes becados y, de otro, a aquellos estudiantes que no alcanzaran a ser beneficiarios, acogerse a las modalidades de pago fraccionado que su misma universidad ofrece al resto de estudiantes. Esta cuestión de plazos en la resolución de las convocatorias de becas parece perjudicar pues involuntariamente a los estudiantes que no resultan beneficiarios y establecen unas condiciones claramente distintas y menos favorecedoras para ellos. Por si no fuera suficiente, algunas universidades suman a este hecho de imposibilitar el fraccionamiento del pago, unos plazos Un adelanto en la convocatoria de Becas y de su consiguiente resolución permitiría a las universidades disponer antes de los ingresos por matrícula de los alumnos becarios y a los alumnos que no resultaran beneficiarios acogerse a las modalidades de pago fraccionado que las universidades ofrecen al resto de estudiantes. 
precio total de la matrícula. Así, por ejemplo, la UEx exige el pago inmediato, la UCM establece tan sólo 5 días hábiles desde la fecha de notificación de la denegación, y la UIB diez días.

\subsubsection{Posibilidades de pagos personalizados y de "pago a la carta"}

El $62 \%$ de las Universidades encuestadas afirman permitir propuestas de pago personalizadas frente al 38\% que no lo permiten. Sin embargo, cuando uno se interesa por conocer en qué supuestos las universidades aceptan el pago personalizado o "a la carta", de forma abrumadora las universidades restringen esa posibilidad a que se acrediten circunstancias personales excepcionales, entre las que se mencionan problemas económicos, situaciones de emergencia social, condiciones de salud graves del estudiante o de quienes sustenten la unidad familiar, etc. Sólo unas pocas universidades afirman facilitar el pago personalizado sin condicionamientos previos (UdLL), o en caso de denegación de beca (URiV, UJI).

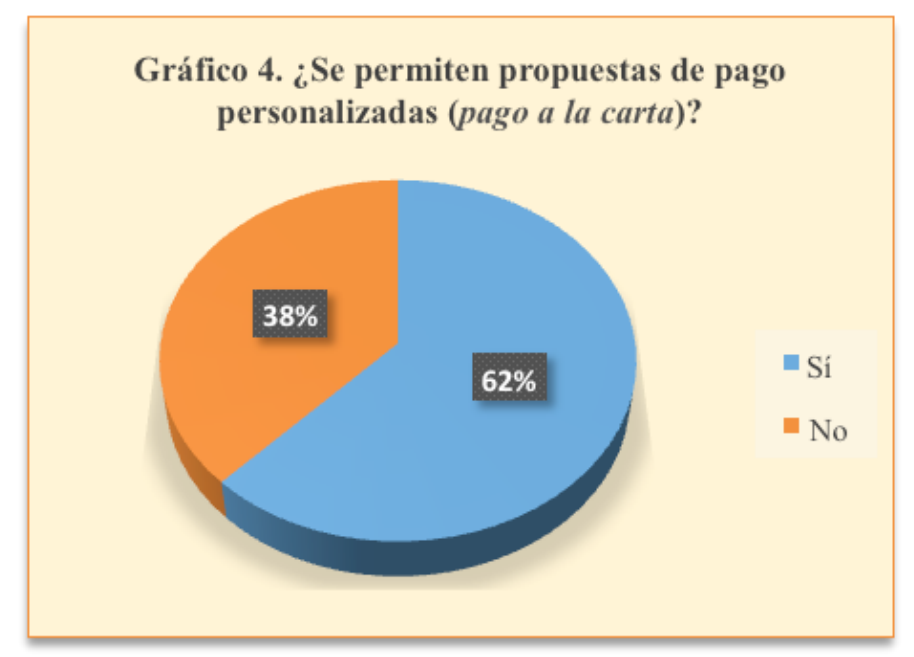

\subsection{Reducción y devolución de los precios de matrícula}

El segundo bloque de preguntas de la encuesta analiza brevemente cuáles son las circunstancias que motivan la reducción del importe de matrícula y en qué normativa se contempla. La práctica totalidad de las universidades contemplan como circunstancias que motivan la reducción del precio de matrícula la obtención de becas, la condición de miembro de familia numerosa, la obtención de premio extraordinario o matrículas de honor, la condición de persona con discapacidad, ser víctima o hijo de víctima de violencia de género o 
ser huérfano de funcionarios civiles o militares fallecidos en acto de servicio. Cabe señalar que dichas causas de exención lo son al amparo de normas estatales, como la Orden de 17 de agosto de 1982 por la que se publican las exenciones, totales o parciales, del pago de las tasas académicas universitarias por matrícula.

Gráfico 5. Circunstancias que motivan la reducción del precio de matrícula (\% de universidades que las contemplan)

Reducción cuando se justifica un suspenso por causas Alumnos integrados en el Fondo Social y Comisiones de Empleados públicos de la Universidad (UEx y UdC) Victimas de violencia de género Huérfanos de funcionarios civiles o militares fallecidos en Víctimas del terrorismo Obtención de premio extraordinario Discapacitados

Beneficiarios del título de familia numerosa Obtención de Matrícula de Honor (en Oviedo sólo $2^{\circ}$ curso

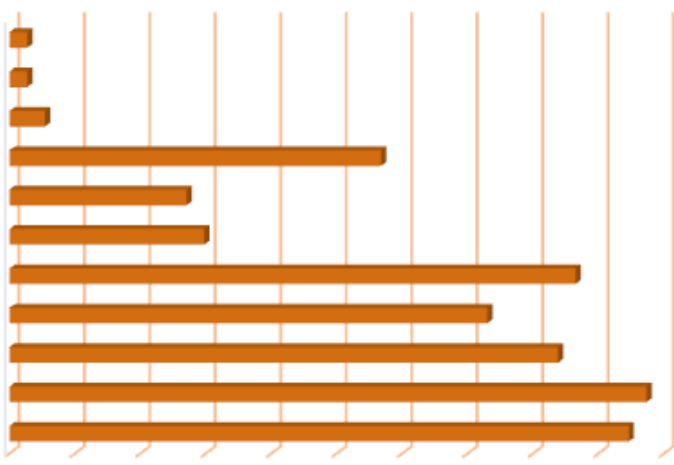


Fuera de estos aspectos reglados, destacan por su anacronismo las bonificaciones sobre los precios de matrícula que conservan para sus hijos los empleados públicos de las universidades de Extremadura y de La Coruña y por lo novedoso del hecho, la reducción en el precio de la matrícula (de segunda a primera matrícula, de tercera a segunda y sucesivamente) que ofrece desde este curso la Universidad de Murcia a los alumnos que puedan justificar no haber superado una determinada asignatura como consecuencia de una causa mayor sobrevenida.

\subsection{Anulación de matrícula: causas, plazos y efectos}

Esta sección de la encuesta analiza con una cierta profundidad el proceso de anulación de matrícula, tanto a instancia del estudiante como a instancia de la propia universidad, sus causas, plazos y efectos.

Cuando un estudiante ya matriculado decide solicitar la anulación de su matrícula, no puede como dijimos anteriormente conseguirlo a no ser que cuente previamente con el visto bueno de la universidad, quien tiene la potestad de concederle o no dicha anulación. Es el ejercicio de esa potestad de la administración universitaria la que necesita ser analiza para explorar los límites en los que puede ejercerse, a fin de evitar que la indefinición de los mismos pueda llegar a vulnerar algún derecho de los administrados, los estudiantes en este caso. Dos hechos influyen a nuestro juicio en la decisión final de la universidad: el momento en el que el estudiante solicita la anulación y los motivos que alega.

El "momento" en que el estudiante solicita la anulación resulta decisivo, como veremos, en determinados supuestos, que sólo tienen sentido si se producen en ciertos momentos del curso académico; igualmente, el "momento" afectará -como ya comentamos- la posibilidad de lograr o no el reembolso de las cantidades satisfechas.

Por su parte, los motivos que los estudiantes pueden alegar son de naturaleza tan diversa que resultaría imposible tipificar todos los supuestos posibles. Digamos pero que grosso modo podemos distinguir entre los motivos que justificarán la petición de una anulación total o sólo parcial de la matrícula. 


\subsubsection{Causas de anulación}

Como puede verse en el Gráfico 6, entre las causas de anulación total se contempla en la totalidad de universidades encuestadas el haber obtenido plaza en otra universidad, circunstancia ésta que sólo opera en el caso de estudiantes de nuevo ingreso.

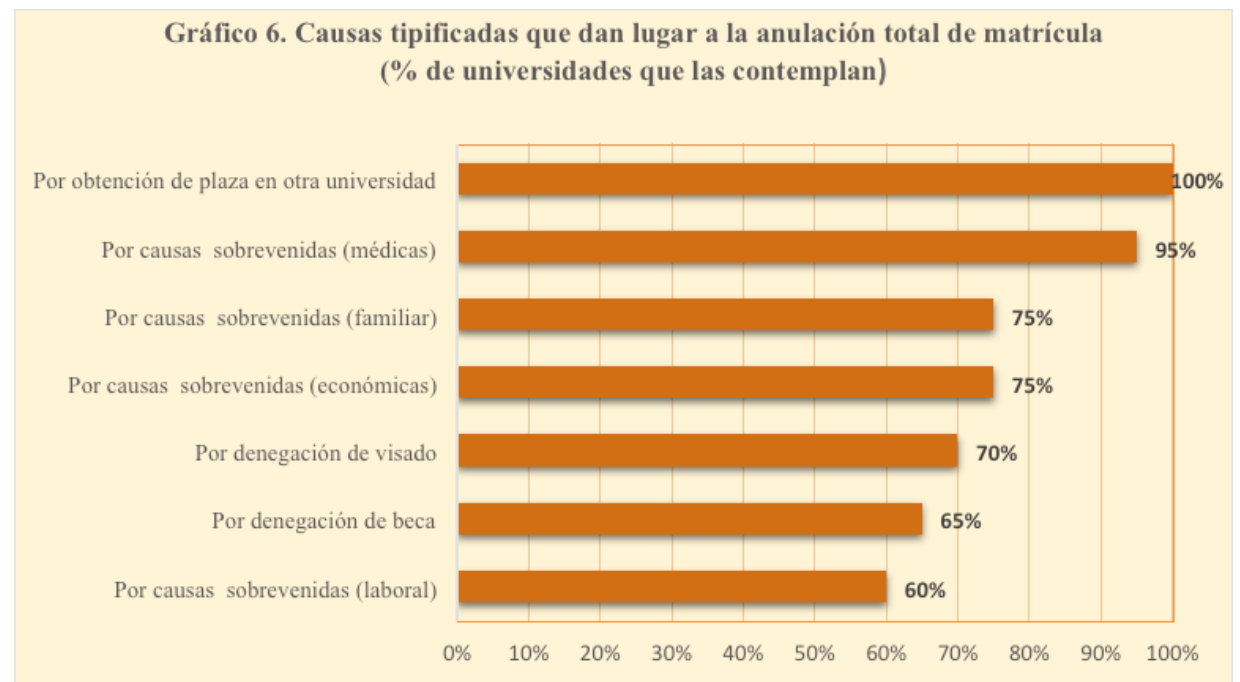

Igualmente, las causas médicas graves, debidamente acreditadas, son habitualmente reconocidas por las universidades como motivo de anulación total de matrícula. Cabe destacar que son pocas las universidades las que contemplan las situaciones "laborales" sobrevenidas como motivo de anulación de matrícula, aun cuando es una de las causas en los últimos años que han provocado un aumento de las quejas y consultas en las Defensorías, probablemente por su falta de regulación. Sería interesante disponer de datos detallados de los casos en los que los estudiantes han solicitado anular total o parcialmente su matrícula alegando "motivos laborales", pues no sólo algunas universidades reportan la existencia de peticiones de anulación relacionadas con la pérdida de empleo o de ingresos de los propios estudiantes por despidos, sino también por lo contrario, por haber obtenido un trabajo -habitualmente precario-, "mini-jobs", pero imprescindible para el sustento familiar, lo que exige para su conservación un horario o dedicación que deviene incompatible con los estudios.

El hecho, por otra parte, de que en ocasiones estos trabajos deban considerarse “irregulares" o "informales" desde el punto de vista de la legislación laboral, impide a los estudiantes acreditar convenientemente su situación y les obliga a renunciar a sus derechos. Es bien conocido cómo la subcontratación, el autoempleo, o el uso de trabajadores externos 
proporcionados por empresas de recursos humanos, disuelve la relación laboral (y por ello los “derechos laborales") (SUBIRATS, 2005).

Como señala la propia Organización Internacional del Trabajo "este proceso aumenta la vulnerabilidad de un número creciente de trabajadores secundarios, limita su carrera profesional y sus perspectivas de formación y perjudica sus condiciones de empleo" (OIT, 2002). Destaca esta última situación por cuanto con frecuencia revela la existencia de situaciones irregulares en la contratación que impiden a los estudiantes acreditar su condición laboral, dificultando la conciliación de los estudios con la vida familiar y laboral lo que favorece su expulsión del sistema educativo.

Con respecto a que la denegación de beca sea uno de los motivos aceptados por la universidad para conceder la anulación de matrícula debe insistirse de nuevo en el beneficio que reportaría al conjunto de la comunidad universitaria un adelanto en la resolución de la convocatoria de becas. El hecho de que la resolución llegue en muchos casos en fecha posterior a que los estudiantes hayan ya completado o casi completado la evaluación de las asignaturas del primer semestre, favorece que algunas universidades no contemplen la denegación de beca como causa de anulación de matrícula, por cuanto argumentan que hacerlo así favorecería que solicitaran la anulación todos aquellos estudiantes que no han superado las A los motivos tradicionalmente alegados por los estudiantes para solicitar la anulación total o parcial de sus matrículas, se han añadido recientemente los motivos "laborales", tanto por haber perdido su empleo como, paradójicamente, "por haberlo encontrado”. Destaca esta última situación por cuanto con frecuencia revela la existencia de situaciones irregulares en la contratación que impiden a los estudiantes acreditar su condición laboral, dificultando la conciliación de los estudios con la vida familiar y laboral lo que favorece su expulsión del sistema educativo. asignaturas matriculadas y sólo acabaran pagando la matrícula los que hubieran

aprobado. Parece claro que aunque no puede descartarse la existencia de esta posibilidad, lo cierto es que los alumnos que han solicitado beca porque real y materialmente no pueden hacer frente al pago de la matrícula pero, pese a ello, por causas económicas relacionadas con los períodos de tributación evaluados u otros, les resulta denegada la beca, enfrentan auténticos problemas para hacer responder de los pagos, pues, como hemos visto en 4.1.1, un $74 \%$ de universidades no les permite el fraccionamiento. Una solución a estos casos pasa por contemplar, al menos entre los supuestos de anulación parcial, la denegación de beca, lo que permitiría a los estudiantes que han matriculado un curso completo (requisito para solicitar la 
beca), anular los créditos no cursados (previsiblemente segundo semestre), ajustando así el coste de la matrícula a sus posibilidades.

Finalmente, cabe señalar que algunas universidades (UB, UIB, UEx) han desarrollado un programa propio de ayudas a circunstancias personales sobrevenidas no necesariamente médicas que intentan evitar el abandono de los estudios y reconducir situaciones personales muy diversas difícilmente categorizables, hacia una normalización que permita la continuidad en los estudios.

Tasados los supuestos en que las Universidades conceden habitualmente la anulación de la matrícula a sus estudiantes, cabe analizar los supuestos en los que es la propia universidad la que de forma unilateral anula la matrícula.

Como puede verse en el Gráfico 7, la totalidad de las universidades encuestadas proceden de oficio a la anulación de la matrícula en el caso de que los estudiantes entre en situación de impago, con independencia de la cantidad adeudada. Este hecho ha adquirido una especial trascendencia estos últimos años, por cuanto ya hemos dicho que la situación de crisis económica ha provocado un aumento de las situaciones en las que muchos estudiantes están teniendo dificultades para pagar los precios públicos de sus estudios.

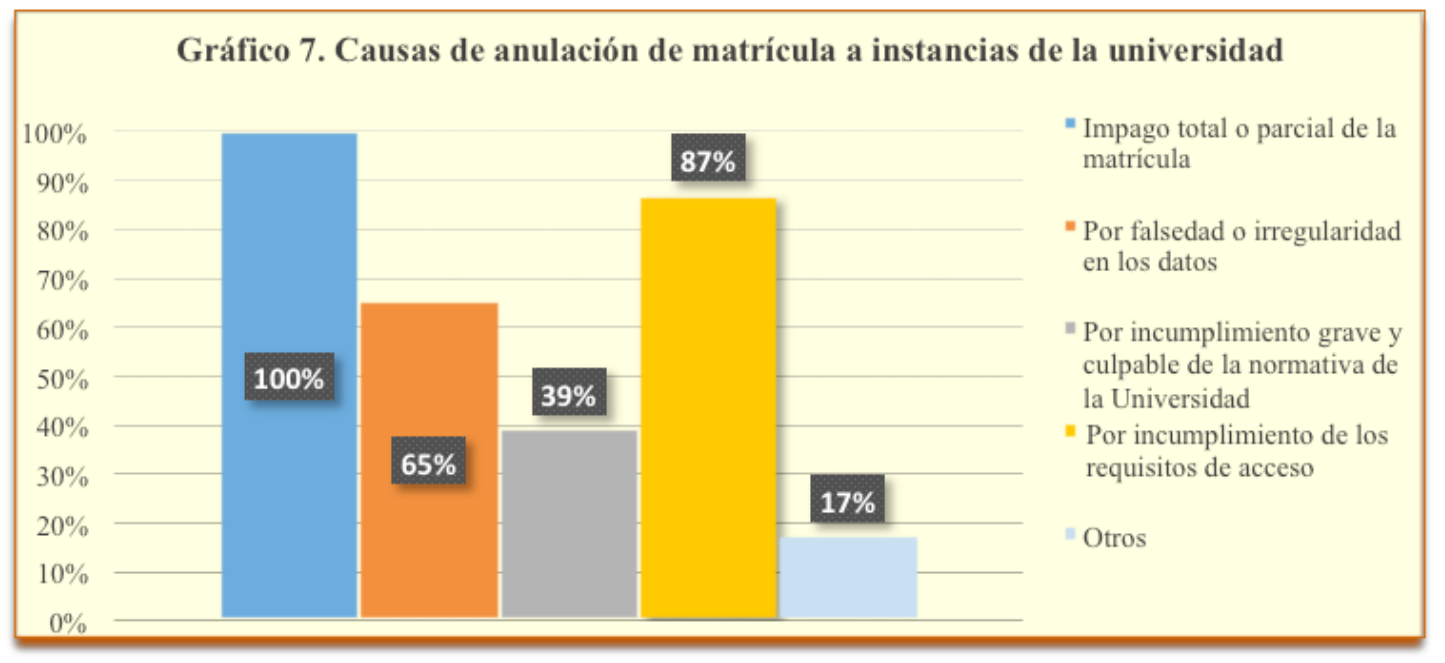

Además del impago, sobre el que volveremos, entre las causas por las que las universidades pueden anular unilateralmente las matrículas se encuentran: la demostración de haber aportado datos falsos o irregulares (65\%), haber incumplido gravemente la 
normativa universitaria $(39 \%)^{9}$, no cumplir con los requisitos de acceso $(87 \%)$ y en un $17 \%$ de las universidades se hallan tipificadas otras causas como: la falta de requisitos académicos exigidos por algunas facultades, la detección de oficio de condiciones de exención de pago no aplicadas, o la superación en el curso anterior de asignaturas vueltas a matricular en el curso siguiente.

\subsubsection{Período o plazo para solicitar la anulación de matrícula}

Preguntadas las universidades sobre si existe un período o plazo establecido en el que los alumnos puedan solicitar la anulación de su matrícula y, de existir, si conlleva la posibilidad de que se reconozca el derecho a la devolución de los importes satisfechos, las respuestas muestran una variada casuística. Como puede verse en la Tabla 6 , un buen número de universidades ofrecen la posibilidad de anular la matrícula hasta una determinada fecha, que suele oscilar entre unos pocos días después de la matrícula y antes del período de inicio de las clases o bien fijar un día -por lo habitual dentro del primer cuatrimestre del curso académico (30 septiembre, 31 octubre, 15 de diciembre, 28 noviembre, 31 diciembre, etc.).

\begin{tabular}{|c|c|c|}
\hline Hasta & Con derecho a devolución & Sin derecho a devolución \\
\hline UAL Hasta 1 marzo & UAH 30 sept/31 octu & UAB 15 sep-7 nov \\
\hline UJA 15 octubre & $\begin{array}{l}\text { UB } 31 \text { octubre } \\
\text { URJC } 30 \text { octubre }\end{array}$ & UJA a partir 15 octubre \\
\hline UNICAN 30 octubre & UM 31 octubre (50\% 1 diciembre) & UB a partir 31 octubre \\
\hline UdC 28 noviembre & UdC hasta 28 noviembre & UJI a partir 1 noviembre \\
\hline UPC 30 noviembre & UCM 15-30 diciembre & U Deusto a partir 7 noviembre \\
\hline UJI 15 diciembre & UJI 15 diciembre & UdC a partir 28 noviembre \\
\hline UPV 31 diciembre & ULEO antes de inicio clases & URJC a partir 30 octubre \\
\hline URJC Todo el curso & $\begin{array}{l}\text { UJA } 10 \text { días después de matricularse } \\
\text { UEM } 15-30 \text { días después de }\end{array}$ & $\begin{array}{l}\text { UCM a partir } 30 \text { diciembre } \\
\text { UPV hasta } 31 \text { diciembre }\end{array}$ \\
\hline UB Todo el curso & $\begin{array}{l}\text { UAL } 5 \text { días después de matricularse } \\
\text { UC.Herrera } 5 \text { días después de UOV }\end{array}$ & $\begin{array}{l}\text { UCM a partir } 31 \text { diciembre } \\
\text { UEMiguel Cervantes a partir } 30 \text { días tras }\end{array}$ \\
\hline UEM Depende del motivo & 30 días antes de evaluación UCLM & UPM Siempre \\
\hline $\begin{array}{l}\text { UOV/UDEUSTO hasta } \\
\text { exámenes/actas }\end{array}$ & $\begin{array}{l}\text { durante período de matrícula } \\
\text { U de Deusto durante período } \\
\text { matrícula/10 días tras matrícula }\end{array}$ & $\begin{array}{l}\text { UCLM Siempre } \\
\text { UEx Siempre, antes de exámenes } \\
\text { ULEO/UAL/UEx antes exámenes }\end{array}$ \\
\hline $\begin{array}{l}\text { UIB } 10 \text { enero (ler semestre) } 10 \\
\left.\text { abril ( } 2^{\circ} \text { semestre }\right)\end{array}$ & UPV antes inicio curso & UdG No está previsto \\
\hline
\end{tabular}

Tabla 6. Periodos en que puede solicitarse la anulación de matrícula y reconocimiento o no del derecho a devolución. Fuente: Encuesta realizada entre los titulares de las Defensorías Universitarias

Esta fecha suele marcar el límite dentro del cual la anulación de matrícula comporta asociado el derecho a la devolución del importe pagado. A su vez, esta fecha suele marcar el

\footnotetext{
${ }^{9}$ Esta causa solo ha sido reportada por Universidades privadas, que disponen por lo general de un reglamento de convivencia, cuyo incumplimiento, dependiendo de la gravedad de los hechos, puede comportar la anulación de matrícula. La ausencia de una legislación reciente que regule el régimen de disciplina académica en las universidades lleva a las universidades públicas a la eterna discusión sobre la aplicabilidad o no del Régimen Disciplinario de 1954 y a hallar en esta falta de definición un argumento con el que justificar el ejercicio más bien escaso de la potestad disciplinaria y sancionadora.
} 
inicio del período en que un estudiante puede solicitar la anulación de su matrícula sin que de concedérsele- tenga derecho a la devolución del importe.

4.3.3. Efectos académicos y económicos de la anulación de matrícula. ¿Nulidad o anulabilidad?

Hemos visto ya que la anulación de matrícula es un procedimiento que puede instarse tanto por parte del estudiante como por parte de la universidad. Resultaría poco sensato suponer que un estudiante se matricule ya con la intención de anular su matrícula, por lo que cabe suponer que no pretenderá tal cosa a menos que tenga fuertes motivos para ello. Todos los motivos que pueden llevar a un estudiante a solicitar la anulación de su matrícula tienen en común una sola cosa: no anular la matrícula supone un perjuicio mayor que conservarla. Analizar pues cuáles son los efectos académicos y económicos que produciría en determinadas circunstancias no conseguir anular la matrícula nos llevará a entender mejor el abanico de situaciones que acaban provocando la petición de anulación por parte los estudiantes.

Cuando un estudiante solicita anular su matrícula es siempre porque conoce una imposibilidad material de cumplir con los estudios de los que se ha matriculado, o porque pretende evitar algunos de los efectos derivados de la no superación de las asignaturas de las que se ha matriculado y anticipadamente prevé. Así, entre las imposibilidades materiales que, lógicamente, le llevarán a pedir la anulación de matrícula están todos los supuestos habitualmente ya contemplados por las universidades en su normativa y que ya hemos examinado en 4.3.1. Dejando aparte los supuestos en que el estudiante matriculado se ve imposibilitado físicamente si quiera de empezar el curso por haber obtenido plaza en otra universidad o por haberle sido denegado el visado, el resto de situaciones tipificadas generalmente como "causas de fuerza mayor" o "circunstancias personales sobrevenidas" son, por propia definición, imprevisibles, por lo que operarán cuando se produzcan y pueden producirse en cualquier momento del curso académico. No obstante, el "momento" en que se produzcan determinará que los efectos académicos o económicos sean distintos e es justa y legal esa diferencia? Examinemos dos supuestos:

\section{La causa de anulación se produce antes de empezar el curso o en sus primeras semanas.}

El hecho de que causas tenidas por justas (una enfermedad grave, un accidente que provoca daños y secuelas importantes, una catástrofe familiar o laboral, etc.) puedan 
sobrevenir en cualquier momento y provocar entonces que un estudiante pida la anulación de su matrícula sólo puede perseguir un objetivo: si el hecho causante se produce antes de iniciar las clases o al poco tiempo de iniciarse, el objetivo es lograr dejar sin efecto la matrícula, es decir, conseguir que la Administración universitaria trate su matrícula como si nunca hubiera existido (lo que en el ámbito contractual privado se conocería como "nulidad"). Los motivos para pedir la anulación de matrícula “a todos los efectos" son tanto de índole

Cuando un estudiante solicita la anulación de matrícula en las primeras semanas del curso espera obtener de la Administración efectos económicos y académicos similares a los que produciría la "nulidad" del acto. económica como académica. Así, desde el punto de vista económico, el estudiante desea

anular la matrícula para lograr la devolución del importe pagado, visto que la inversión realizada anticipadamente no podrá ser aprovechada, y el dinero de la matrícula podrá darse por perdido. Igualmente, desde el punto de vista académico es imprescindible que logre la nulidad total de su matrícula, puesto que las consecuencias de no hacerlo son extremadamente perjudiciales: constará en su expediente que no se ha presentado a ninguna asignatura, no aprobará ninguna, por lo que incumplirá probablemente con el régimen de permanencia, lo que a su vez puede impedirle reiniciar sus estudios y cuando pueda hacerlo, dependiendo de que su universidad mantenga o no la "dispensa automática de convocatoria", deberá pagar una segunda matrícula.

\section{La causa de anulación se produce a mitad de curso o prácticamente al final}

En cambio, cuando las causas tenidas por justas sobrevienen una vez iniciado el curso, avanzado éste o incluso cercana a su finalización, el objetivo que pretende lograr el estudiante no es dejar sin efecto la matrícula, sino conservar lo hecho hasta el momento y conseguir la anulación de lo que reste desde el momento en que se produjo la causa y la finalización del curso; es decir, el estudiante pretende conseguir que la Administración universitaria anule su matrícula con efectos sólo parciales o relativos (lo que se conocería en el ámbito contractual como "anulabilidad"), conservando por ello todos los efectos -especialmente académicosexistentes hasta que se produjo la causa que va a impedir que el estudiante "cumpla", por así decirlo, con su parte del "contrato" (asistencia a clase, rendimiento académico, superación de asignaturas, etc.).

Los motivos para pedir la anulación de matrícula "con efectos relativos", limitados o parciales, son mucho menos de índole económica y mucho más de índole académica. Ya 
hemos visto en el apartado 3.1. que las Universidades, al menos en el marco de la Administración Pública, no pueden proceder a la devolución de precios públicos en cualquier momento, sino sólo antes de que se inicie la actividad y cuando el servicio no se preste "por causas no imputables al obligado al pago" ${ }^{10}$, por lo que si la petición de anulación de matrícula se produce una vez la actividad está iniciada y avanzada no procedería devolución alguna del importe satisfecho a excepción -a nuestro juicio- de la parte proporcional del servicio que el "obligado al pago" no haya podido recibir por causas no imputables a él mismo.

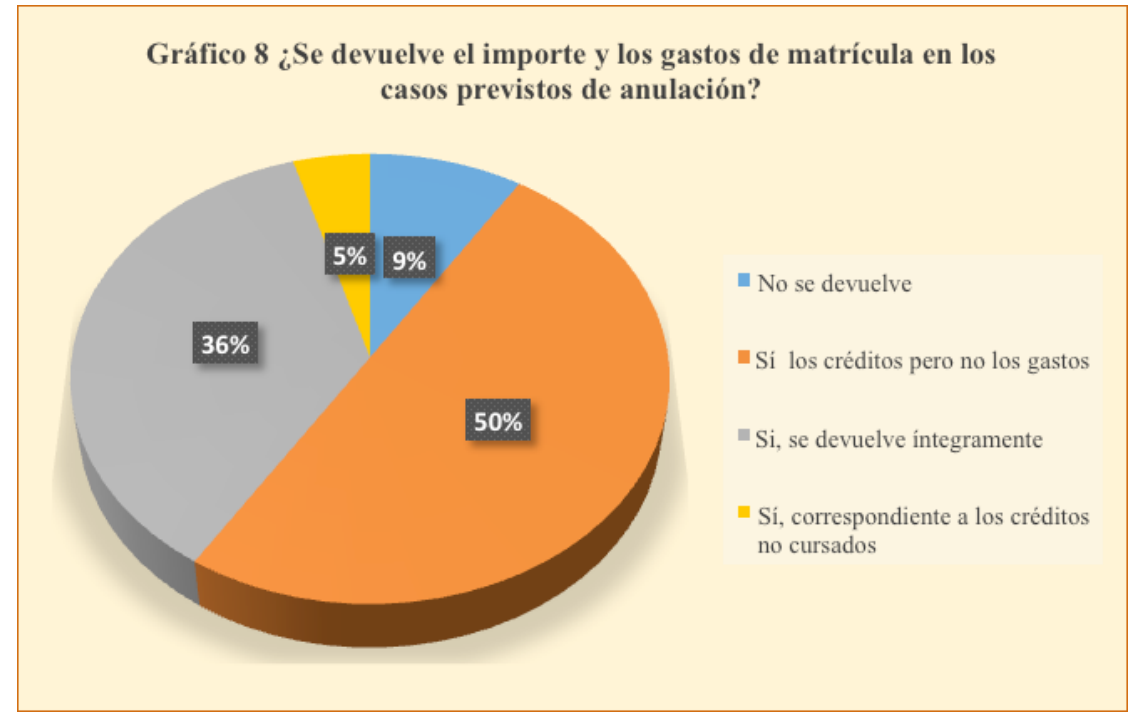

Observando las respuestas de las universidades participantes en la encuesta en relación a si se devuelven o no los importes íntegros (incluidos gastos administrativos) cuando se produce la anulación de matrícula en los casos previstos de anulación, se ve (Gráfico 8) que en 11 de las universidades (50\%), la anulación de la matrícula comporta la devolución de los importes satisfechos a excepción de los gastos administrativos ${ }^{11}$; en 8 de las universidades ${ }^{12}$ $(36,4 \%)$ la devolución es íntegra en los supuestos tipificados; por su parte, en dos (9\%) de ellas no se devuelve nada ${ }^{13}$ y en una $(4,5 \%)$ se reintegra el importe de los créditos no cursados ${ }^{14}$. Este último es a nuestro parecer el procedimiento que mejor se ajusta a lo establecido en la

\footnotetext{
${ }^{10}$ Artículo 27 de la Ley 8/1989 de Tasas y Precios Públicos.

${ }^{11}$ Sí devuelven importe pero no los gastos: UJI,UJA;UCM, UEMH, ULL, URJC,UAL, UPC, UNICAN, UCLM, UIB.

${ }^{12}$ Se devuelven importes y gastos: UAH, UPV, UDC,UPV,UEM,UM,UOVI,UCH-CEU.

${ }^{13}$ No se devuelve nada: UdC y UEx.

${ }^{14}$ IE Universidad.
} 
Ley de Tasas y Precios Públicos y al concepto de "anulabilidad" que pretenden normalmente los estudiantes cuando piden, ya avanzado el curso, la anulación de su matrícula. No puede afirmarse que el montante de estas devoluciones vaya a afectar gravemente el equilibrio presupuestario de las universidades públicas, por cuanto las matrículas anuladas no comportan la devolución más que de la pequeña parte del coste total que asumen los estudiantes y sus familias.

Como señalábamos, una vez avanzado el curso, las peticiones de anulación de matrícula que realizan los estudiantes persiguen en todo caso eliminar los efectos académicos negativos que provocará el eventual abandono de sus tareas académicas por las causas alegadas. Entre las principales, evitar la evaluación de asignaturas de las que se prevé un mal resultado debido a la imposibilidad de asegurar el rendimiento académico, lo que a su vez evitará el pago de una segunda o tercera matrícula en cursos posteriores.

El hecho de que un buen número de universidades mantengan aún las "convocatorias” y las "dispensas automáticas de convocatoria" evita sin duda que los alumnos se vean obligados a pedir la anulación parcial de matrícula para eliminar el efecto negativo que producen las ausencias en la evaluación. Sin embargo, algunas universidades han eliminado el concepto de "convocatoria" sustituyéndolo por el de "matrícula", de manera que una vez matriculada una asignatura sólo cabe aprobarla, pues de no ser así, el curso siguiente deberá considerarse segunda o sucesiva matrícula, con independencia de que la calificación obtenida sea "no presentado" o "suspenso".

\section{Efectos de la anulación que se produce a instancias de la Universidad}

Nos queda por analizar qué efectos académicos y económicos se producen cuando la anulación de la matrícula se realiza a instancias de la Universidad. Ya comentamos que en este caso, la anulación es unilateral y que la causa que en todas las universidades comporta la anulación de matrícula es el impago total o parcial de la matrícula (vid. Gráfico 9). Al ser ésta, a la vez, la causa más directamente relacionada con la actual crisis económica, pues el aumento de los impagos no es atribuible a la despreocupación o al descuido, merece la pena analizar qué consecuencias económicas y académicas tienen estas anulaciones. 
Preguntadas las universidades sobre los efectos que produce sobre los estudiantes la

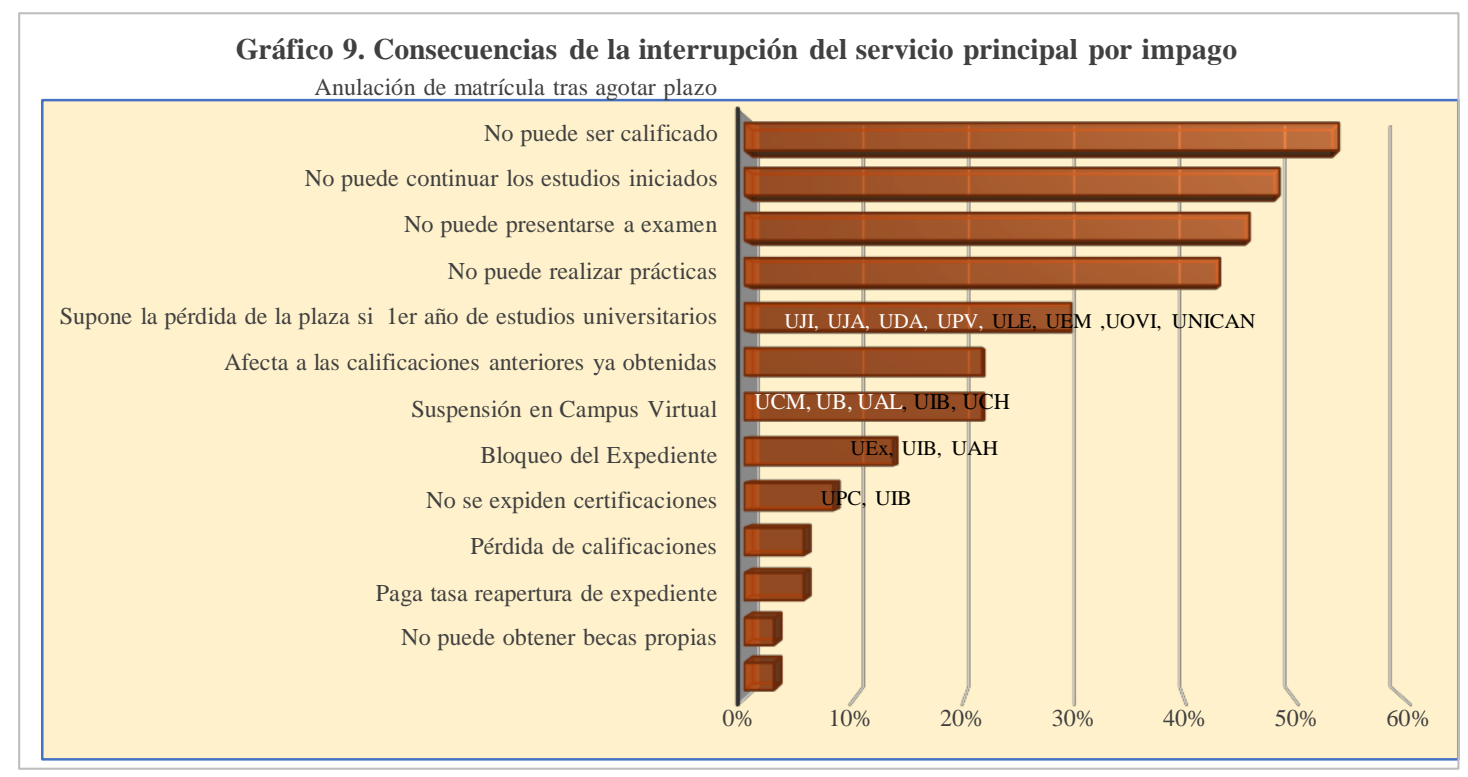

situación de impago, 23 han contestado que provoca la suspensión del servicio principal (79\%), mientras que 6 contestan que dichos servicios no se interrumpen $(21 \%)^{15}$.

Explorando qué significa la interrupción del servicio principal, vemos que dicha interrupción significa en más 50\% de los casos "anulación de matrícula" tras agotar el plazo $^{16}$, "no ser calificado”, "no poder presentarse a examen”, "ver afectadas a las calificaciones ya obtenidas", "no poder continuar estudios”, "no poder realizar prácticas”, "suspender el perfil del campus virtual", "bloquear el expediente", "no expedir certificaciones”, "perder calificaciones”, "pagar tasas de reapertura”, "no poder optar a becas propias”, etc. Cualquiera de estas consecuencias no es exclusiva, pues de hecho muchas de ellas se dan simultáneamente en muchas universidades.

Como vemos, las universidades adoptan todo tipo de medidas para forzar a los estudiantes a regularizar su situación de impago sin distinguir en muchas ocasiones el pago fuera de plazo de una auténtica situación de morosidad. Lo más preocupante bajo nuestro punto de vista es que en algunas universidades las consecuencias derivadas de una situación de impago devienen permanentes, aun después de que el estudiante haya regularizado su situación económica (p.e. la UIB hasta el curso pasado, o la Universidad de León). En la mayoría de universidades, los efectos de estas drásticas medidas son "temporales", de manera

\footnotetext{
${ }^{15}$ El impago no interrumpe la prestación del Servicio principal en UAB, UAL,UPC, U.Deusto, UJ.orge, U.Cardenal Herrera.

${ }^{16}$ Veremos a continuación cuál es ese plazo.
} 
que duran mientras perdura el impago. No obstante, si éste se dilata en el tiempo, igualmente se producen efectos muy negativos, especialmente si los estudiantes no pueden ser calificados, no se les permite asistir a exámenes, realizar prácticas o si ven bloqueado su acceso al campus virtual.

Los medios que utilizan las universidades para "forzar" a sus estudiantes a pagar no son propios de una administración pública y creemos que el ejercicio de la autonomía universitaria no incluye utilizar vías distintas a las legalmente establecidas para exigir el pago de los precios públicos, como son los recargos, la vía de apremio, el constreñimiento de bienes, etc.

En no pocas universidades, además de ver restringidos todas las actividades que comporta el servicio principal (calificaciones, prácticas, acceso a campus virtual, de los estudios), la situación de impago se extiende a otros servicios universitarios.

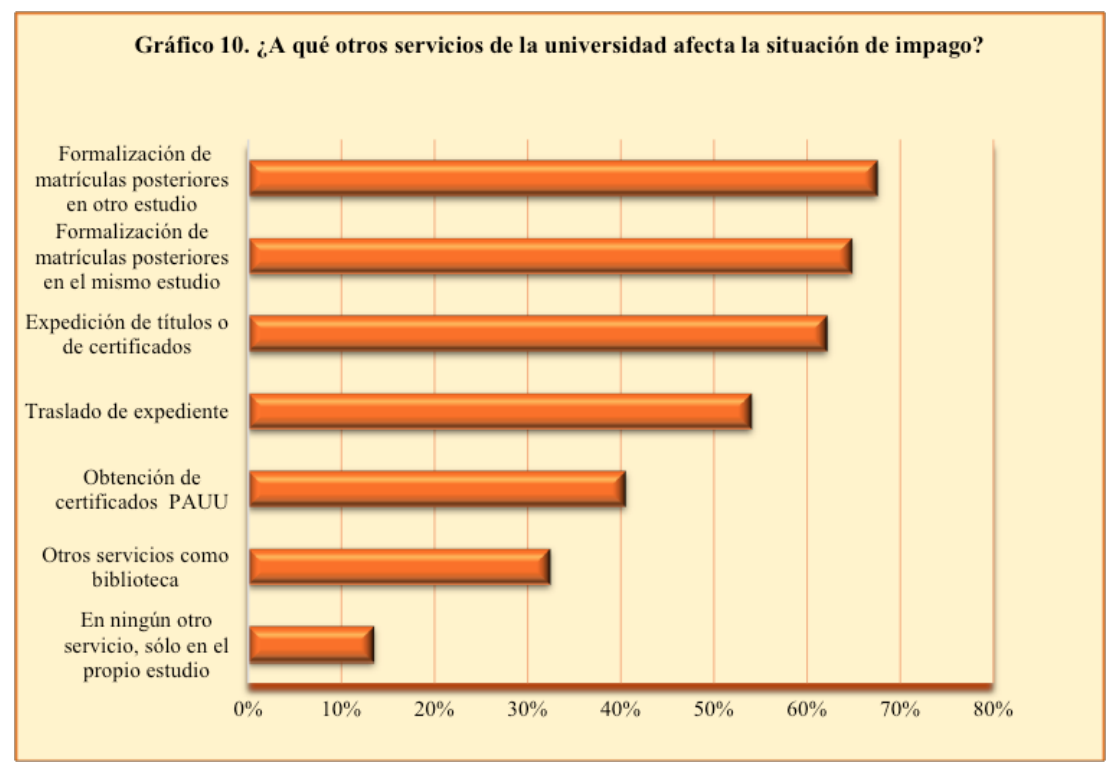

Entre los más frecuentes, se encuentra la imposibilidad de realizar matrículas posteriores en ese mismo estudio o en otro, impedir el traslado de expediente, el acceso a la biblioteca y también lo que a nuestro juicio ha de considerarse del todo punto censurable, que es la prohibición de expedir certificados y títulos. Teniendo en cuenta de las situaciones de impago constituyen faltas administrativas (no son delitos) y que la Administración pública tiene establecidas las vías por las que se reclaman los precios públicos adeudados, resulta contrario a derecho utilizar como vía de constreñimiento la vulneración de un derecho fundamental, como podría ser por ejemplo el derecho al libre ejercicio de la profesión. Así por ejemplo, una universidad que se estuviera negando a expedir un título que habilita para el ejercicio de una 
profesión, como medida de presión para que el titular del derecho pague una deuda administrativa contraída por otro servicio, estaría a nuestro juicio extralimitándose en sus funciones, ejerciendo un auténtico abuso de poder, equivalente, por poner un ejemplo, al que supondría impedir ejercer el derecho a voto en las elecciones municipales a un vecino que deba una o varias mensualidades -supongamos- del abono de la piscina municipal. La desproporción es manifiesta.

A poco que se revise la modernización que ha realizado la Hacienda Pública española, tanto la estatal como la comunitaria, además de las haciendas locales -en especial de las grandes ciudades- en lo que respecta a fraccionamientos de pago, introducción de períodos de pago voluntario, procedimientos de compensación de deudas, pago a la carta, flexibilidad en los plazos y cuotas etc., se comprobará que la institución universitaria, pese a haber incorporado las nuevas tecnologías en la mayor parte de sus procedimientos, permanece aún por lo que se refiere a las estructuras administrativas y especialmente contables, bastante $\operatorname{atrasada}^{17}$. Por su parte, las comunidades autónomas, que podrían haber mejorado los procesos de gestión económica de las universidades que financian, han mantenido una distancia a la larga perjudicial para la propia institución universitaria, que por supuesto debe tener y mantener -a nuestro juicio- su autonomía universitaria en el ejercicio de su libertad académica, que incluye la de cátedra, docencia e investigación, sin sujeción ni limitación a doctrinas instituidas ni censura, pero que no ampara el dictado de cualquier tipo de normativa, por más que pretenda contribuir a desanimar en su práctica a estudiantes potencialmente deudores.

Aunque en más de un 75\% de las universidades se restablecen a los estudiantes sus derechos, recuperando sus calificaciones y reconocimientos que quedaron sin efecto como consecuencia de la "anulación" de matrícula que provocó el impago, sólo en el 34\% de las universidades se inicia el procedimiento de apremio, que es el legalmente previsto para perseguir a los deudores de precios públicos.

En unas pocas universidades, el pago fuera de plazo comporta un recargo adicional que o bien es una cuantía fija (UJA: 59,10€ tasa de reapertura; UPC: $12 €$ por la suspensión temporal y $20 €$ de reapertura o ULL: $50 €)$ o bien un porcentaje sobre el importe adeudado (del $4 \%$ en UCM/UPM/UAH/U3C/UAM, $5 \%$ UIB y 10\% UPC).

\footnotetext{
${ }^{17}$ Baste recordar a estos efectos el atraso en el desarrollo de la contabilidad analítica que debería posibilitar un mejor conocimiento de los costes reales de las diferentes actividades en relación con la financiación pública y privada, desconociéndose aún hoy el coste real de todas las titulaciones en España.
} 


\subsection{Procesos de notificación de la anulación o situación de impago}

Un $71 \%$ de las universidades encuestadas responden que el modo mayoritario de proceder a la notificación de una situación de impago o de una anulación de matrícula es una carta postal con acuse de recibo; el segundo medio, que no excluye en todos los casos el anterior, es el envío de un aviso en la plataforma digital (29\%); y el tercer medio es el aviso telefónico $(25 \%)^{18}$.

Se ha preguntado expresamente si la universidad contempla la notificación telemática, entendiendo por ésta, un procedimiento autentificado, cifrado y seguro de notificación que ofrece la misma seguridad jurídica para el emisor y el receptor que el tradicional método del envío certificado (con tarjeta rosa) o el burofax. Sólo 12 universidades disponen de este procedimiento: UJA, UJI, UPV, UCM, UdG, UEM, URJC, UAL, UNIOVI, UCH-CEU, IE Universidad y UAH.

Un $60 \%$ de los defensores considera que los alumnos no están suficientemente informados de la existencia de esta vía de notificación y consideran que no ofrece suficientes garantías de recepción a los estudiantes. La mayor parte de los defensores que han respondido que desconocen si los estudiantes han dado su consentimiento expreso para que la vía telemática sea la vía exclusiva de notificación, lo que es un requisito para garantizar la legalidad del procedimiento y seria, en caso de litigio, causa suficiente como para estimar las reclamaciones que eventualmente presentaran los estudiantes contra actos administrativos (la anulación de matrícula por ejemplo) que les limitara derechos.

Por su parte, preguntados acerca de si el procedimiento de notificación telemática permite que se tenga constancia de la recepción por parte del interesado de la información, así como de la fecha, identidad y contenido del acto notificado, el 73\% opina que sí y el 19\% que no.

Igualmente, más del $70 \%$ de los defensores considera que en el caso de que la Universidad requiera un pago pendiente, informa suficientemente a los estudiantes de los efectos económicos y académicos que conlleva el impago de matrícula.

Por último, el 90\% de los defensores afirma que existen posibilidades de reactivar la matrícula anulada una vez que se regulariza la situación de impago, pero sólo un 67\% afirma que se informa convenientemente a los alumnos de cómo realizar tal la activación. Los textos

\footnotetext{
18 Cabe recordar que hasta el año 2013, el Decreto de Precios Públicos que regulaba la prestación de servicios universitarios de la Universidad de les Illes Balears establecía extemporáneamente que la anulación de matrícula se producía al día siguiente de producirse el impago y sin notificación previa, lo cual, como hemos visto, constituye una práctica totalmente irregular en el ámbito de la administración y de la relación contractual.
} 
de las notificaciones que por una u otra vía hacen llegar las universidades a los interesados contiene, a juicio de la mayoría de defensores (valores cercanos al 82\%), el texto íntegro de la resolución, indica los recursos procedentes, órgano ante quien deben interponerse y plazos, e indicación de si se ha agotado o no la vía administrativa.

Algunos defensores han coincidido a la hora de valorar el proceso de notificación que sus universidades realizan a sus estudiantes como poco garantista. Se reconoce también la virtud de los procedimientos telemáticos por cuanto, de existir, suponen un ahorro de tiempo y de trabajo de tramitación administrativa considerable, especialmente para el Personal de Administración y Servicios.

\section{Conclusiones}

Hemos visto cómo los procesos de anulación de matrícula y sus efectos derivados, como es la devolución de importes cuando procede, es una cuestión que ha cobrado importancia en la actual época de crisis, tanto porque se ha incrementado el número de alumnos que han pedido anular su matrícula al no poder continuar sus estudios, como porque las universidades han procedido a la anulación de matrículas como forma habitual de responder a las situaciones de impago.

Tras analizar mediante una encuesta las normas que rigen en las universidades los procesos de anulación de matrícula, hemos extraído las siguientes conclusiones:

1. Existe en la mayoría de universidades una fecha límite hasta la cual los alumnos pueden solicitar la anulación parcial/total de matrícula sin necesidad de ninguna justificación; una vez pasada esa fecha, la solicitud de anulación parcial / total debe ser justificada, sirviendo a estos efectos las causas preestablecidas como "justas" para determinar qué solicitudes merecerán la devolución del importe y cuáles no (por lo general, no se devuelve el importe cuando las matrículas son anuladas a petición del estudiante sin que este alegue causa considerada justa).

2. Existe grosso modo, diferencias entre las universidades privadas y las universidades públicas sobre los plazos para anular la matrícula y los procesos. Al no estar las universidades privadas sometidas a los mismos procedimientos administrativos que las universidades públicas, pueden tener procesos más flexibles, proclives a la negociación y al cierre de acuerdos más personalizados. 
3. El acto de matricularse es necesariamente bilateral, ha de contar con la voluntad expresa de un sujeto de contratar el servicio académico que oferta la universidad, en cambio, el acto de anular la matrícula puede ser unilateral, por parte de la universidad, y cuando se insta a petición del alumno, necesariamente debe contar con el beneplácito de la universidad.

4. Hay que desterrar el término "tasas" para hablar de los "precios públicos", pues hay una diferencia sustancial a la hora de poder exigir la devolución de los segundos mientras que es mucho más difícil pedir la devolución de tasas.

5. De acuerdo con la Ley 8/1989, de 13 de abril, de tasas y precios públicos "los precios públicos podrán exigirse desde que se inicia la prestación de servicios que justifica su exigencia”, de manera que el pago anticipado de la matrícula es una condición contractual libremente aceptada, por lo que si la anulación de matrícula se produce antes de iniciarse la prestación de servicios, queda plenamente justificada la devolución de la totalidad del importe satisfecho.

\section{Resultados de la encuesta}

6. Se extrae como conclusión general de la encuesta realizada que en prácticamente todas las universidades existe el pago fraccionado y en un $61 \%$ de las mismas se ofrece a los estudiantes 5 plazos o más, lo que es altamente recomendable.

7. No es habitual que se ofrezcan en las universidades públicas bonificaciones por pronto pago, como sí hacen algunas universidades privadas, pues persiste la idea de que ofrecer distintos precios según el momento de pago resulta discriminatorio, cuando sólo lo sería si estuviéramos ante una tasa.

8. La relación Alumno becario-matrícula genera un abanico de casos muy problemáticos:

- El hecho de que los alumnos que estudian con beca no paguen a matrícula, sino que el importe de las mismas las pague el Estado a las universidades, genera en las universidades con precios públicos superiores a la cuantía con la que el Estado concede a beca, a soportar el diferencial de precio

- Los alumnos que han solicitado beca y no resultan beneficiarios deben hacer frente al pago de su matrícula en condiciones distintas y peores que el resto. La resolución tardía, una vez bien avanzado el curso, obliga (iobliga.) a las universidades a exigir el pago de la matrícula en un solo pago y en un plazo muy breve de tiempo. $63 \%$ impide fraccionar, aunque un $62 \%$ permite "negociar el pago") 
9. La política de precios públicos permitiría establecer una gama de precios variada: con bonificaciones, exenciones y condiciones que podrían ser distintas más allá de las causas de exención o reducción que están tipificadas por Ley (discapacidad, violencia de género, víctimas terrorismo, familia numerosa, etc.)

10. El "momento" en el que el estudiante pide la anulación de su matrícula y la devolución de su importe es decisivo para el éxito de su pretensión. El momento determina si el estudiante tiene o no derecho a recuperar el dinero pagado:

- Desde que se matricula y paga (todo o parte) hasta una fecha que debería coincidir con el inicio de curso, el alumno debería poder anular su matrícula con efecto económico y recibir la totalidad del importe satisfecho SIN necesidad de exponer causa alguna. La anulación tendría efectos de nulidad total y eliminaría también eventuales efectos académicos (no implicaría segundas/terceras matrículas, no agotaría convocatorias...)

- Una vez iniciado el curso, la anulación sólo puede ser total o parcial por causa justificada. Si se acepta la existencia de causas "sobrevenidas", entonces no puede establecerse un período en el que pedir la anulación total o parcial, pues la misma naturaleza de lo imprevisto, impide tal previsión. La anulación por causa justa debería mantener siempre los efectos académicos de las actividades realizadas hasta el "momento" en que se sobrevino la causa y suspender los efectos académicos de ahí en adelante (supuesto de anulabilidad)

11. La causa más frecuente por la que la universidad insta la anulación de la matrícula es precisamente la falta de pago de la misma.

12. El impago produce consecuencias académicas inmediatas, que se utilizan como coacción para obligar al pago, cuando la falta del pago no puede provocar la suspensión del servicio contratado sin notificación y preaviso, período de prórroga y conllevar, en caso de persistir el impago a las vías administrativas para la reclamación (apremio, constreñimiento, etc., incluyendo intereses de demora y posteriormente recargo).

13. Es contrario a derecho que la anulación de matrícula por impago pueda producir efectos académicos permanentes sobre el período que permaneció impagado, puesto que para ser así, la declaración de nulidad debería ser total y en ese caso afectaría también el importe. Si el alumno paga la matrícula y lo hace fuera del plazo establecido pueden devenir consecuencias económicas (intereses de demora, recargos etc.) pero pueden derivar consecuencias académicas más que de un impago persistente, que no se salda. 
14. La Universidad no puede impedir el uso de sus servicios académicos como medida coercitiva para obligar al pago de otros servicios que se adeudan, máxime cuando la no prestación de dichos servicios supongan un obstáculo administrativo que perjudique al estudiante en el ejercicio de sus derechos fundamentales.

15. Las universidades parecen utilizar medios para el cobro de sus impagados que no están acordes con los tiempos actuales, pues todas las administraciones ofrecen sus servicios en condiciones cada vez más favorables y adaptadas a sus ciudadanos.

16. Probablemente por la existencia de una equivocada acepción del concepto de autonomía universitaria, las CCAA no han regulado suficientemente los mecanismos de pago y cobro de los precios públicos universitarios. La autonomía universitaria y la legítima pretensión de cobrar en tiempo y forma por los servicios académicos prestados no puede amparar mecanismos coercitivos como los que se utilizan.

17. Los procesos de notificación de la anulación de matrícula o de la situación de impago son, a juicio de las defensorías, mejorables y ofrecer más garantías procesales a los alumnos. Se echa en falta una mejor explicación de cómo "reactivar" la matrícula una vez que la universidad la anuló.

18. Se observa una baja implementación de los procesos de notificación telemática con uso de firma electrónica y certificación cifrada y con comprobación de recepción. Se sigue haciendo uso casi exclusivo de los procedimientos postales y cuando se utilizan plataformas digitales, éstas carecen de seguridad jurídica y de validez de notificación.

Reflexiones y recomendaciones realizadas por los Defensores universitarios tras el debate de este texto

1. Que las causas que sean tenidas por justas para dar lugar a la anulación de matrícula deben operar para las peticiones de anulación total durante todo el curso académico.

2. Que sería justo -como mínimo- establecer un período en el que la composición formal de una matrícula pudiera modificarse libremente sin coste alguno ni necesidad de justificación.

3. Que ninguna de las partes que integran el precio final de la matrícula debe ser considerada "tasa”, por lo cual la devolución, cuando resulte procedente, deberá ser íntegra.

4. Que no parece que puedan establecerse exenciones ni tampoco retenciones en ningún caso salvo las que se recojan expresamente en el Decreto de precios públicos que a estos efectos apruebe la Comunidad Autónoma, el cual -a su vez- estará a lo que disponga el 
resto de normativa vigente (régimen especial de las personas becarias, víctimas de violencia de género o de actos terroristas, familias numerosas, monoparentales, etc.).

5. Que las modificaciones en la composición de la matrícula que se realicen durante el período que reglamentariamente se establezca debe dar lugar a las liquidaciones económicas que correspondan.

6. Que una vez cerrado el plazo en el que se acepten modificaciones en la composición de la matrícula, parece razonable que la anulación parcial de los efectos académicos de la matrícula sólo pueda ser estimada por causa justa y en ningún caso parece que deba dar lugar a devolución del importe pagado o a la anulación del importe comprometido a pagar.

7. Que de fijarse una fecha máxima para modificar o anular entrega la matrícula, todas las modificaciones o anulaciones hechas dentro de plazo deben dar lugar a la devolución del importe, para lo cual la prestación del servicio no deberse haber iniciado. Lo anterior hace necesario que el plazo de matrícula y de modificación/anulación de la misma no pueda alargarse mucho más allá del inicio de clase de cada semestre.

8. Que en los casos de anulación de matrícula en los que el alumno, por alguna razón, haya quedado como deudor, la administración universitaria está obligada a dar por prescrita la deuda generada sin necesidad de que el interesado lo pida, siempre que hayan transcurrido cinco años desde la última reclamación de la misma, pues la única forma que tiene la Universidad de interrumpir el cómputo del plazo de preinscripción es reclamando la deuda.

9. Que debe promoverse el uso de la notificación telemática con plenas garantías jurídicas, incluyendo la obtención del consentimiento informado del alumno y los medios de notificación y autenticación que correspondan, sin excluir otras vías (SMS, correo electrónico, etc.).

10. Que en aras de mejorar la comprensión de las actuaciones administrativas y de evitar el sentimiento de injusticia, incomprensión y frustración que se genera entre los alumnos, la Universidades debería mejorar sus procesos de comunicación. A cualquier ciudadano que no conozca en profundidad el funcionamiento de la administración pública le cuesta entender que una vez que se le ha anulado la matrícula y ha dejado de asistir a clase, se le exija el pago íntegro de unos servicios que a su juicio no ha recibido (caso por ejemplo de las asignaturas de segundo semestre).

11. Que no existe derecho ni prerrogativa alguna de la administración universitaria que ampare actuaciones abusivas y desproporcionadas, de manera que frente al impago, y aun a 
riesgo de que el alumno se declare insolvente, debe utilizar las vías previstas en las normas reguladoras del procedimiento recaudatorio en vía ejecutiva.

12. Que debe vigilarse estrechamente que los Decretos de Precios públicos o en su defecto las normativas propias de las universidades apliquen convenientemente las exenciones al pago de matrícula que corresponde a las personas con discapacidad, a las víctimas de terrorismo y a las víctimas directas de violencia de género y de sus hijos, en este último caso con independencia de la fase del proceso judicial en que se encuentre la declaración de dicha condición, que además, se adquiere a perpetuidad, aun cuando falleciera el agresor.

13. Que los sistemas informáticos de las universidades contemplen todas las opciones académicas posibles en que puede encontrarse un alumno en situación de impago, de manera que pueda reactivarse de forma inmediata su expediente académico una vez regularizada la situación.

\section{Bibliografía}

Escardíbul Ferrá, J.O.; Oroval Planas, E. (2011): "Análisis del sistema actual de precios públicos y de ayudas al estudio en la universidad española y de su previsible evolución”. Lecturas sobre economía de la educación: [homenaje a María Jesús San Segundo], 2011, ISBN 978-84-694-9578-() , págs. 61-78.

Fachelli Oliva, S.I.; Dani Torrents, D.; Navarro Cendejas, J. (2014): “ ${ }_{\mathrm{C}}$ La universidad española suaviza las diferencias de clase en la inserción laboral? Revista de educación, ISSN 0034-8082, № 364, 2014, págs. 119-144.

Hernández Armenteros J, Pérez García JA (2011) La financiación universitaria española. Nuevas perspectivas en un horizonte de austeridad y compromiso social. En Nuevas Perspectivas para la Financiación y el Gobierno de las Universidades. Fundación Europea Sociedad y Educación Studia XXI. Fundación Europea Sociedad y Educación. №6. ISBN 978-84-695-1130-5. Madrid. 2011.

Julià, J.F; Pérez, J.A.; Meliá, E. (2014): "El cambio necesario de la universidad española ante un nuevo escenario económico". Interciencia JAN 2014, VOL. 39 № 01.

Michavila, F. (2012): La Universidad Española en cifras”. CRUE.

OCDE (2012) Educatión at a Glance 2012: OCDE indicators. Organización para la Cooperación y el Desarrollo Económico. París, Francia. 570 pp.

ORGANIZACIÓN INTERNACIONAL DEL TRABAJO (2002): Informe sobre el empleo en el mundo 2001 , OIT.

Subirats i Humet (dir.); Gomà Carmona, R. Y Brugué Torruella, J. (coord.) (2005): Análisis de los factores de exclusión social. Institut del Govern i de Polítiques Publiques, UAB. Fundació BBV, Barcelona. 


\section{ANEXO}

Consecuencias de la denegación de beca sobre el pago

o sobre las modalidades de pago

1. ¿Qué consecuencias tiene en el pago o en las modalidades de pago la no obtención de beca?

\begin{tabular}{|c|c|}
\hline Universidad & Respuesta \\
\hline UJA & $\begin{array}{l}\text { Se tienen que poner al día en los pagos no realizados hasta ese momento. También } \\
\text { pueden solicitar la ayuda social urgente de la UJA. }\end{array}$ \\
\hline UJI & Se pasa un solo recibo (suele ser en mayo). Se aceptan propuestas personalizadas. \\
\hline UGM & Debe procederse al pago íntegro del importe del precio público. \\
\hline UEMCERVAN & Ninguna \\
\hline UPV & $\begin{array}{l}\text { Los estudiantes que tienen aplazada el pago de la matrícula esperando la beca pueden } \\
\text { incorporarse a la modalidad de pago aplazado. }\end{array}$ \\
\hline IdG & Se exige el pago (pero se pueden negociar las fracciones) \\
\hline UAB & $\begin{array}{l}\text { Si el alumno realiza la matrícula como becario sólo paga las tasas correspondientes. Si con } \\
\text { posterioridad al alumno le deniegan la beca, debe pagar el importe total de la matrícula } \\
\text { sin posibilidad de realizar pago fraccionado. }\end{array}$ \\
\hline UdLleida & $\begin{array}{l}\text { Que se ha de pagar la matrícula en efectivo. Se puede solicitar aplazamiento si existe } \\
\text { "situación socioeconómica familiar especialmente grave" }\end{array}$ \\
\hline UdXiga & $\begin{array}{l}\text { Una vez solicitada beca, como la resolución es posterior al último plazo de pago ya no se } \\
\text { puede optar al pago fraccionado. }\end{array}$ \\
\hline IdA & Que sólo se abonan las tasas administrativas en un solo pago. \\
\hline UB & $\begin{array}{l}\text { La solicitud de beca conlleva matrícula condicional. } \mathrm{Si} \text { la solicitud de beca no prospera, se } \\
\text { intenta fraccionar el pago resultantes al menos en dos plazos }\end{array}$ \\
\hline UPV & $\begin{array}{l}\text { Las personas que al formalizar la matrícula no hubieran abonado los precios } \\
\text { correspondientes por solicitar la concesión de una beca y les sea denegada } \\
\text { provisionalmente la misma, deberán abonar el precio correspondiente a la matrícula que } \\
\text { efectuaron con independencia de que presenten alegaciones contra la denegación de la } \\
\text { beca. }\end{array}$ \\
\hline UPM & Ninguna. \\
\hline URJC & $\begin{array}{l}\text { Se debe pagar la matrícula completa. En ese caso hay pago fraccionado, aunque las becas } \\
\text { suelen resolverse a finales de curso y sería muy dificil hacerlo. }\end{array}$ \\
\hline UdLean & $\begin{array}{l}\text { Si no se obtiene beca se debe pagar la matrícula como el resto de los alumnos } \\
\text { matriculados }\end{array}$ \\
\hline UEM & Debe pagar la totalidad en los plazos establecidos por la universidad \\
\hline $\mathbf{U M}$ & No pueden acogerse, de oficio, al pago fraccionado, aunque pueden solicitarlo al Rector \\
\hline UPF & Que se tiene que pagar el importe de los precios públicos \\
\hline UAL & $\begin{array}{l}\text { La posibilidad de fraccionamiento de la matrícula hasta en cinco pagos (siempre que } \\
\text { cumpla los umbrales establecidos) }\end{array}$ \\
\hline UCM & $\begin{array}{l}\text { El Decreto 80/2014, de } 12 \text { de julio, del Consejo de Gobierno de la Comunidad de } \\
\text { Madrid, por el que se establecen los precios públicos por servicios universitarios en la } \\
\text { Comunidad de Madrid, establece como consecuencia la obligatoriedad del abono del } \\
\text { precio, y su impago conlleva la anulación de la matrícula en todas las materias, } \\
\text { asignaturas o disciplinas (art. 19).Las normas de matrícula de la UCM 2014-15 establecen } \\
\text { la obligatoriedad de regularizar la matrícula en el plazo de } 5 \text { días hábiles denegación de la } \\
\text { beca, permitiendo acogerse al fraccionamiento hasta antes del } 20 \text { de enero. }\end{array}$ \\
\hline UPM & La reclamación al estudiante de la totalidad de la matrícula. \\
\hline UOVI & Ingreso del importe total de la matrícula, en un pago único. \\
\hline UGAN & Ninguna \\
\hline URiX & Se genera el recibo del precio público pendiente de pago \\
\hline UGLM & Ninguna \\
\hline $\begin{array}{l}\text { IE } \\
\text { Universidad }\end{array}$ & Ninguna \\
\hline U de Deusto & En principio, ninguna. \\
\hline UAH & Pagar la matrícula \\
\hline U San Jorge & Ninguna \\
\hline UIB & $\begin{array}{l}\text { Hasta 2013-14 los alumnos que pierdan la beca o no se les conceda la exención de } \\
\text { matrícula están obligados a abonar el importe total en un plazo de diez días naturales } \\
\text { desde la notificación personal de denegación o la publicación de la resolución definitiva de } \\
\text { concesión y denegación de las becas. Desde } 2014-15 \text { la no concesión de beca por motivos } \\
\text { económicos da derecho a anular la matrícula, en cuyo caso la universidad puede cobrar el } \\
25 \% \text { del importe. }\end{array}$ \\
\hline UEX & Se le pide que pague de inmediato la matrícula \\
\hline
\end{tabular}


2. ¿Qué consecuencias tiene en el pago o en las modalidades de pago la revocación de la beca concedida?

\begin{tabular}{|c|c|}
\hline Universidad & Respuesta \\
\hline UJA & $\begin{array}{l}\text { Se tienen que poner al día en los pagos no realizados hasta ese momento. } \\
\text { También pueden solicitar la ayuda social urgente de la UJA. }\end{array}$ \\
\hline UJI & ver anterior \\
\hline UCM & Debe procederse al pago íntegro del importe del precio público. \\
\hline UE-MGERVAN & Depende de cada caso particular \\
\hline UPV & $\begin{array}{l}\text { La revocación de la beca implica el pago de las tasas correspondientes. Se les } \\
\text { puede autorizar el pago aplazado de estas tasas. en cualquier caso antes del } \\
\text { final de la docencia deberá estar liquidada la matrícula. }\end{array}$ \\
\hline UdG & Como en el caso anterior \\
\hline UAB & Normalmente esta situación no se da. \\
\hline UdLleida & La posibilidad de exigir la devolución de la beca \\
\hline UdVigo & No se puede fraccionar el pago una vez denegada la beca. \\
\hline UdG & Que se tiene que abonar la matrícula en un solo pago sin opción a fraccionar \\
\hline UB & $\begin{array}{l}\text { La revocación de beca no tiene consecuencias en el pago de la matrícula, sí } \\
\text { que las tiene en cuanto suponen la devolución del importe correspondiente a } \\
\text { la ayuda }\end{array}$ \\
\hline UPV & Se deberá abonar el precio de la matrícula \\
\hline UPM & No lo sé es para prueba \\
\hline URJC & $\begin{array}{l}\text { Ninguna, puesto que la revocación llega algún tiempo más tarde. Ocurre } \\
\text { que si no se abona la cantidad adeudada a la Universidad el/la estudiante no } \\
\text { puede acceder a los servicios de la universidad: nueva matrícula, solicitud de } \\
\text { certificados, etcétera. }\end{array}$ \\
\hline UdLeon & $\begin{array}{l}\text { Si se revoca la beca se debe pagar la matrícula como el resto de los alumnos } \\
\text { matriculados }\end{array}$ \\
\hline UM & $\begin{array}{l}\text { Se les reclama el abono de la beca y, en la práctica, pueden negociar su } \\
\text { fraccionamiento }\end{array}$ \\
\hline UPF & $\begin{array}{l}\text { Ninguna, pues se puede pedir beca adelantando el primer plazo de su } \\
\text { matrícula, que posteriormente se devuelve. }\end{array}$ \\
\hline UAL & $\begin{array}{l}\text { El alumno vendrá obligado al abono del precio correspondiente a la } \\
\text { matrícula }\end{array}$ \\
\hline UCM & $\begin{array}{l}\text { No prevé la normativa dicha circunstancia, si bien podría hacerse una } \\
\text { interpretación analógica de la normativa establecida para la denegación de } \\
\text { la beca. }\end{array}$ \\
\hline UPC & La reclamación al estudiante de la totalidad de la matrícula. \\
\hline UOVI & Ingreso del importe total de la matrícula, en un pago único. \\
\hline UNICAN & Ninguna \\
\hline URiV & Se genera el recibo del precio que no cubre la beca \\
\hline UCLM & Imposibilidad de fraccionamiento del pago \\
\hline $\begin{array}{c}\text { IE } \\
\text { UNIVERSIDAD }\end{array}$ & Ninguna \\
\hline UAH & Pagar la matrícula \\
\hline UEX & Ninguna \\
\hline UIB & $\begin{array}{l}\text { Se exige el pago íntegro de la matrícula revocada. Si se anula totalmente, se } \\
\text { cobra el } 25 \% \text {. }\end{array}$ \\
\hline
\end{tabular}


3. ¿En qué supuestos se acepta el pago "a la carta”?

\begin{tabular}{|c|c|}
\hline Universidad & Respuesta \\
\hline UJA & $\begin{array}{l}\text { De forma fraccionada en pagos hasta en cinco plazos, para aquel alumnado que asíl lo solicite cuyos } \\
\text { umbrales de renta y patrimonio familiar calculados conforme establece el Capítulo IV del Real Decreto } \\
472 / 2014 \text {, de } 13 \text { de junio, no superen el ciento diez por ciento del extremo superior del intervalo } \\
\text { correspondiente establecido para el umbral } 3 \text {. }\end{array}$ \\
\hline UJI & En el de becas no concedidas. \\
\hline UPV & Excepcionalmente. \\
\hline UdG & Petición razonada y voluntad de pago demostrada (es decir, que ha pagado los fraccionamientos anteriores) \\
\hline UdLL & Se admite sin condicionamientos previos. \\
\hline UB & $\begin{array}{l}\text { Sólo en casos excepcionales justificados en que se pueda llegar a razonar que los supuestos normativos no } \\
\text { son suficientes. }\end{array}$ \\
\hline UdLe & En situaciones excepcionales de falta de recursos económicos para hacer frente al pago de la cuota normal \\
\hline UEM & Cuestiones personales, familiares... \\
\hline UM & $\begin{array}{l}\text { Cuando el estudiante no puede hacer frente al pago en los plazos establecidos. He tenido algún caso en que } \\
\text { se ha permitido finalizar el pago en septiembre para poder afrontarlo con el dinero obtenido trabajando en } \\
\text { verano. }\end{array}$ \\
\hline UAL & $\begin{array}{l}\text { Se podrá establecer un fraccionamiento de pago diferente, siempre que concurran en la persona solicitante } \\
\text { circunstancias que lo justifiquen suficientemente }\end{array}$ \\
\hline UGard.Herr & Demostración problemas económicos \\
\hline UGM & $\begin{array}{l}\text { No existe normativa específica sobre la cuestión, si bien sí se contemplan supuestos de devolución del } \\
\text { importe de la matrícula en casos excepcionales por causa de fuerza mayor sobrevenida y debidamente } \\
\text { documentada, tales como enfermedad grave del estudiante o familiar en primer grado. }\end{array}$ \\
\hline UIB & No está fijado en la normativa, aunque puede solicitarse al Rector. \\
\hline UPG & En caso de situaciones económicas complicadas. Se gestionan individualizadamente. \\
\hline URiV & $\begin{array}{l}\text { Excepcionales, cuando se ha denegado la beca y siempre de forma individualizada teniendo en cuenta las } \\
\text { circunstancias especiales de cada estudiante. }\end{array}$ \\
\hline UGLM & Emergencia social, situaciones de desempleo \\
\hline Ud Deusto & Depende de las circunstancias personales y/o familiares. Se estudia cada caso. \\
\hline UAH & Condicionados a estudio de situaciones particulares, previa resolución del Vicerrector. \\
\hline
\end{tabular}

